Research Article

\title{
Identification of Far-Field Long-Period Ground Motions Using Phase Derivatives
}

\author{
Minghui Dai $\mathbb{D},{ }^{1}$ Yingmin Li $\mathbb{D}^{1},{ }^{1}$ Shuoyu Liu, ${ }^{2}$ and Yinfeng Dong ${ }^{1}$ \\ ${ }^{1}$ College of Civil Engineering, Chongqing University, Chongqing 400045, China \\ ${ }^{2}$ College of Engineering and Technology, Southwest University, Chongqing 400715, China
}

Correspondence should be addressed to Minghui Dai; fzudmh@163.com

Received 22 December 2018; Accepted 10 March 2019; Published 29 May 2019

Academic Editor: Harry Far

Copyright (c) 2019 Minghui Dai et al. This is an open access article distributed under the Creative Commons Attribution License, which permits unrestricted use, distribution, and reproduction in any medium, provided the original work is properly cited.

\begin{abstract}
The characteristics of long-period ground motions are of significant concern to engineering communities largely due to resonance-induced responses of long-period structures to far-field long-period ground motions which are excited by the existence of distant sedimentary basins. Classifications of records enable applications of far-field long-period ground motions in seismology and engineering practices, such as attenuation models and dynamic analysis of structures. Accordingly, the study herein aims to develop an approach for identifying the far-field long-period ground motions in terms of the later-arriving long-period surface waves. Envelope delays derived from phase derivatives are employed to determine the later-arriving long-period components on the basis of phase dispersion. A quantitative calibration for long-period properties is defined in terms of the ratio of energy from later-arriving long-period components to the total energy of a ground motion. In order to increase the accuracy of candidate farfield long-period records caused by sediments, recording stations within basins or plains are collected from the K-NET and KiKnet strong-motion networks. Subsequently, the motions are manually classified into two categories in order to form a training dataset by visual examinations on their velocity waveform. The two predictive variables, including the corner frequency obtained from envelope delays and the corresponding energy ratio, are used for the establishment of the classification criterion. Furthermore, the analysis of classification results provides insight into the causes for discrepancy and verifies the effectiveness of the proposed method. Finally, comparisons of the mean normalized acceleration response spectrum with respect to the predictors, as well as the local site effects, are performed.
\end{abstract}

\section{Introduction}

Far-field long-period ground motions result in the resonant shaking of long-period structures to an extent which is in excess of that predicted based on the intensity of the motions. It is well documented that the primary causation of resonantinduced responses during the 1985 Michoacan earthquake may be attributed to far-field long-period motions; structures in Mexico city (located approximately $400 \mathrm{~km}$ to the epicenter) were damaged to a more significant degree than those adjacent to near faults. Hereafter, a number of studies on farfield long-period ground motions have been conducted in the realms of both engineering and seismology. Subsequent events, such as 1999 Chi-Chi, 2003 Tokachi, 2004 off peninsula, 2008 WenChuan, and 2011 Tohoku earthquake [1-4], have permitted researchers to recognize the vulnerability of structures with an intrinsic long-period to far-field long-period motions, even if their amplitude is relatively small at distant sedimentary layers. Generally, far-field long-period motions are mostly distinguished themselves by the presence of later-arriving surface waves, consisting of long-period components, which are manifested in the form of the sinusoidal waves in a velocity time series [5,6]. Furthermore, the performance of high-rise buildings subjected to far-field longperiod motions was investigated considering the inclusion of the effects of SSI, suggesting that long-period surface waves make the significant contribution to structural responses relative to that from body waves [11]. 
Compared with near-fault ground motions which feature distances normally confined to $50 \mathrm{~km}$, as inferred from the literatures $[6,12]$, the present paper is concerned with long-period ground motions which are generated in distant sedimentary layers. In consideration of "pulse-like motions" with long-period characteristics, as suggested by researchers $[13,14]$, far-field long-period motions are denominated "long-period motions" in an attempt to differentiate two terminologies. On the contrary, ground motions with predominantly high frequencies are referred as "non-longperiod ground motions."

It is beneficial to enrich recorded collections of longperiod ground motions for the electronic database in practical studies. Specifically, a database of long-period motions for the purpose of conducting the assessment pertaining to long-period structures is available to engineers; furthermore, the prediction of whether a ground motion in a given seismic environment will contain laterarriving long-period surface waves is readily performed by seismologists. However, identification of long-period motions in past studies almost depends on individual judgments, and thus varied classifications from researchers give rise to an impediment in reproducing results associated with long-period properties due to the lack of a quantitative criterion.

As seen in Figure 1(a), for example, the recorded velocity series, ILA056NS, Chi-Chi, M7.6, and earthquake, presents long-period surface waves in a series of full cycles. It is clear that such long-period waves arrive later than body waves which feature high-frequency components, thus extending the duration of the shaking process and further accounting for the increased amplitudes. In view of this, this motion is inarguably identified as a long-period ground motion. In contrast, a visual examination, allowing for the classification of TCG006NS from Iwate-Miyagi Nairiku, M7.2, earthquake, shown in Figure 1(b), presents challenges due to an absence of apparent full cycles from the corresponding velocity-time history. Because of this, classifying such motion by means of visual examination seems ambiguous. The velocity-time history for HDKH06NS, Tokachi, M8, earthquake, shown in Figure 1(c), is undoubtedly classified as a non-long-period motion due to the lack of visible long-period waves.

Knowledge of the mechanism of long-period ground motions is essential in order to permit the differentiation of their characteristics from non-long-period ground motions. In general, it is recognized that an appearance of surface waves by the conversion of body waves at margins of either basins or plains with sedimentary wave guides is an outstanding feature $[5,15-17]$. In the vein of this notion, the schematic plot is presented in Figure 2, which delineates variations in the velocity waveforms relative to the geological site. This suggests that arrival times are dependent upon frequencies on the basis of phase dispersion. Additionally, path effect, mentioned in consideration of completeness but without discussing details herein, is treated as another factor [18-20] which results in amplifications of the surface waves over specific periods, accounting for overlapping of multipathing surface waves along propagation [5].

However, considering complicated rupture processes and the trajectory of the source to engineering sites, it seems difficulties in collecting seismological information if the determination of long-period motions in practice is required. The quantitative criterion, therefore, is developed based on the analysis of the properties of long-period ground motions themselves rather than explorations over their origins based on seismological knowledge, which is beyond the scope of the present discussion. Instead, as inferred from the articles $[5,15,20]$, envelope delays derived from phase derivatives are capable of capturing variations of arrival times with frequencies. Thus, the influences of long-period surface waves on lengthening duration of ground motions are proposed [21]. Furthermore, the velocity structure pertaining to layered media with the aid of envelope delays is approximately formulated, and the reliability of the corresponding results is validated with reference to geological investigations $[5,22]$.

In this article, the proposed method for the identification of long-period ground motions employs phase derivatives, by which the later-arriving long-period components (mostly consisting of long-period surface waves) can be detected. The rationale behind this method is manifested by the measurement of contributions from the later-arriving long-period surface waves to the ground motion in terms of energy. In this respect, the later-arriving long-period components in the frequency domain are obtained by the calculation of envelope delays, which indicate relative arrival time dependent on frequencies. Then, a quantitative assessment of long-period characteristics relative to the ground motion is performed on the basis of later-arriving long-period components. The ground motions library of K-NET and KiK-net strong-motion networks, Japan, are used for collections of preliminary candidate long-period ground motions. The resulting quantitative criterion is proposed as the result of logistic regression. Furthermore, examinations of classification results are performed in order to verify the effectiveness of the proposed method. In addition, variations of longperiod properties from classifications are investigated by means of normalized acceleration response spectra.

\section{Proposed Method for Identification}

2.1. Envelope Delay. It is documented that surface waves travel at a lower velocity than body waves, resulting in variations of phase arrivals which are frequency dependent $[5,20]$. In relation to this, envelope delays calculated from phase derivatives [15] are adopted herein in order to facilitate the detection of long-period components.

Based on the theorem of Fourier transform, we can readily write a pair of equations as follows: 


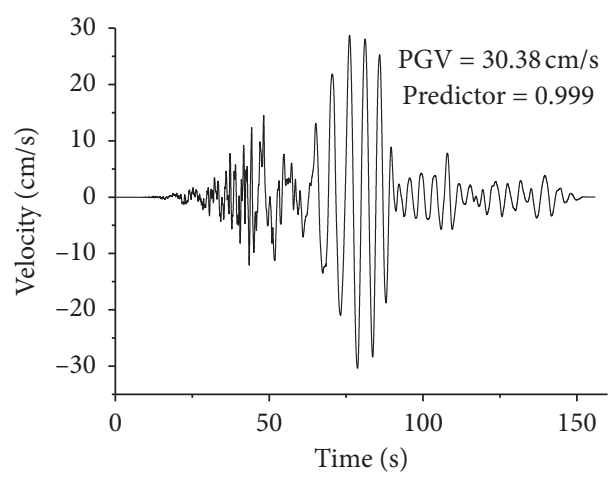

(a)

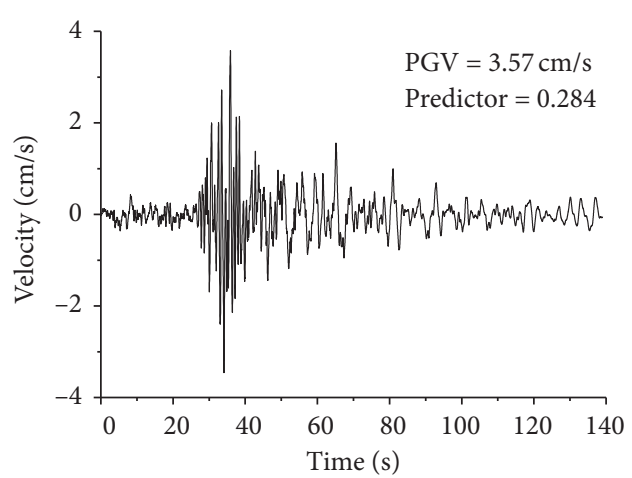

(b)

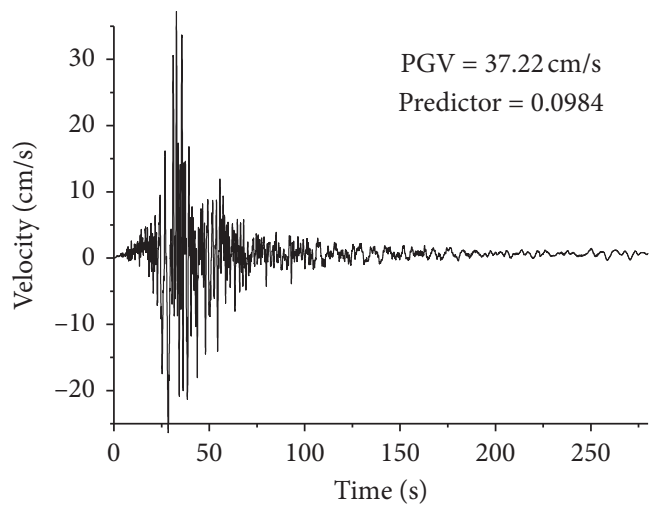

(c)

FIGURE 1: Examples of velocity histories for recordings from (a) 1999 ILA056NS, Chi-Chi, M7.6, earthquake; (b) 2008 TCG006NS, IwateMiyagi Nairiku, M7.2, earthquake; (c) 2003 HDKH06NS, Tokachi, M8, earthquake, respectively.

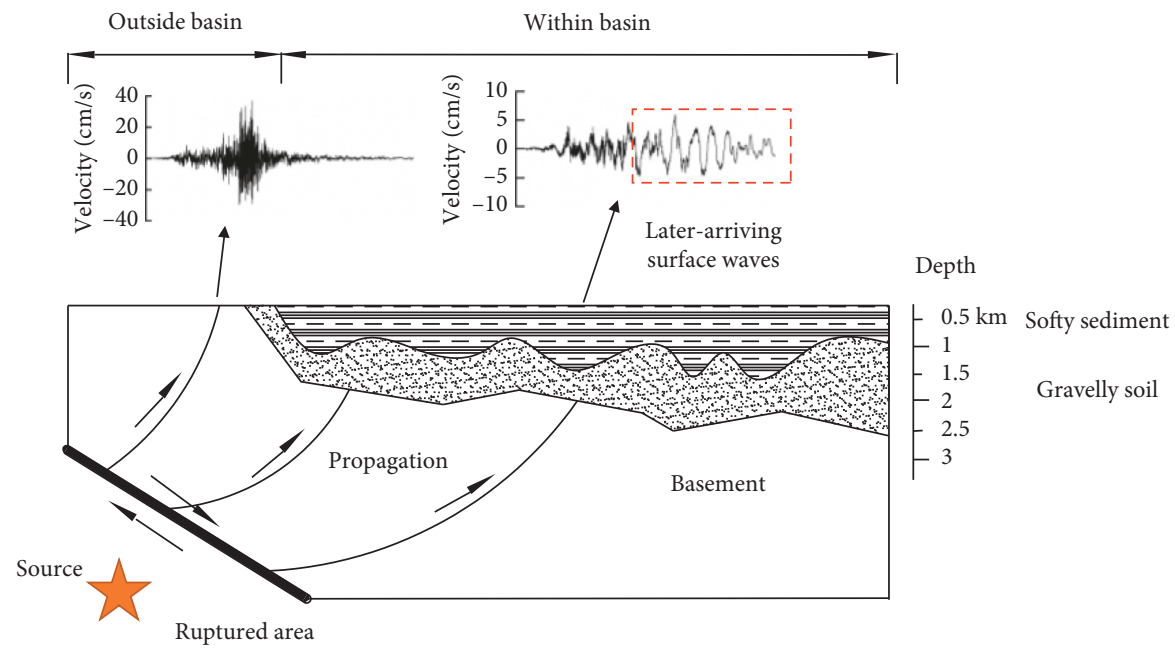

FIgURE 2: The schematic plot illustrates the mechanism for long-period ground motions.

$$
F(w)=\int_{-\infty}^{+\infty} f(t) e^{i w t} d t
$$

$$
\text { Also } F(w)=A(w) e^{i \theta(w)}
$$

where both amplitude $A(\omega)$ and phase $\theta(\omega)$ are functions of angular frequency $\omega$, both of which are treated as the result of the conversion process of a time series signal $f(t)$ into complex amplitudes $F(w)$ to form a frequency domain representation by means of the Fourier transform; $A(\omega)=$ $\sqrt{\operatorname{re}[F(\omega)]^{2}+\operatorname{im}[F(\omega)]^{2}}$ and $\theta(\omega)=\arctan (\operatorname{im}[F(\omega)] /$ re $[F(\omega)])$; re $[\cdot]$ and im $[\cdot]$ are real and imaginary component operations, respectively.

Taking the logarithm on both sides of equation (2) and performing differentiation with respect to angular frequency 
$\omega$, the form can be written after performing the imaginary component operation:

$$
\operatorname{im}\left[\frac{d F(w)}{F(w) d w}\right]=\frac{d \theta(w)}{d w} .
$$

Furthermore, equation (1) is substituted into equation (3) after differentiation of equation (1) with respect to angular frequency $\omega$, and then equation (3) can be recast in the form as follows:

$$
\operatorname{im}\left[\frac{i G(w)}{r e[F(w)]+i \operatorname{im}[F(w)]}\right]=\frac{d \theta(w)}{d w},
$$

where

$$
i G(w)=i \int_{-\infty}^{+\infty} t f(t) e^{i w t} d t
$$

Finally, the mathematical expression for phase derivatives by simplification of equation (4) is given as

$$
\frac{d \theta(w)}{d w}=\frac{\operatorname{re}[G(w)] \operatorname{re}[F(w)]+\operatorname{im}[G(w)] \operatorname{im}[F(w)]}{\operatorname{re}[F(w)]^{2}+\operatorname{im}[F(w)]^{2}} .
$$

It is worth noting that equation (5) implies the centroid time of an angular frequency $\omega$ over the entire time series. In essence, it represents the relative arrival time of a particular angular frequency $\omega$. Thus, variations in relative frequencybased arrival times can be estimated using frequency-dependent envelope delays in the context of phase dispersion $[15,21]$.

In order to illustrate the difference between envelope delays in terms of velocity waveforms, two examples are shown in Figure 3. The velocity time series for CHBH12NS, Tohuku, M9, earthquake and corresponding envelope delays derived from its acceleration time series are shown in Figure 3(a) and Figure 3(b), respectively. It is found that the differences in arrival times are particularly obvious at between frequencies lower than $2.12 \mathrm{~Hz}$ and above, as is consistent with the observations which indicate that the long-period surface waves arrive later relative to high frequencies in Figure 3(a). In contrast, Figure 3(d) for the record ISK004EW from Niigataken Chuetsu-oki, M6.8, earthquake shows that arrival times for low frequencies are not as sensitive as those from CHBH12NS. However, from the two examples, it is clear that the majority of arrival times for high frequencies coincide with the time point at which the peak value of their time history occurs.

According to the observations delineated in Figure 3, a trend is derived pertaining to the sensitivity of envelope delays to low frequencies which mostly account for laterarriving surface waves, while arrival times corresponding to high frequencies are correlated substantially with the time wherein the peak value occurs. Thus, herein a two-piecewise frequency function is adopted in order to capture envelope delays, as similarly suggested by Boore [15]. Arrival time $t(f)$ dependent on frequency is given as

$$
t(f)= \begin{cases}\alpha \ln (f)+\beta, & f \leq f_{\text {corner }}, \\ t\left(f_{\text {corner }}\right), & f>f_{\text {corner }},\end{cases}
$$

where the frequency variable is attained from $f=w / 2 \pi$; the corner frequency $f_{\text {corner }}$ is used to identify the components which exhibit arrival times with sensitivities to low frequencies; correspondingly, $t\left(f_{\text {corner }}\right)$ represents the arrival time for the majority of high-frequency components by the assumption that their envelope delays are insensitive to frequencies; the coefficient $\alpha$ reflects the change of arrival times in terms of frequencies lower than $f_{\text {corner; }}$; and the constant $\beta$ is used to ensure the mathematical significance of the frequency-based function, especially as the limit of $\ln (\cdot)$ tends to exhibit negative infinity when the variable of frequency approaches zero. It is necessary to note that the plots for envelope delays in this paper are illustrated in the form of arrival times $(\mathrm{sec})$ and frequency $(\mathrm{Hz})$ on the abscissa and ordinate, respectively, in an attempt to make satisfactory comparisons with the corresponding time series.

The least squares approximation considering the weight function is introduced for the purpose of obtaining the coefficients of $\alpha, \beta, f_{\text {corner }}$, and $t\left(f_{\text {corner }}\right)$ by minimizing the integrated square difference between actual envelope delays $\hat{t}(f)$ and the assigned model $t(f)$, so the objective function $\hat{\alpha}$ is expressed as

$$
\hat{\alpha}=\arg \min _{\alpha} \int_{0}^{f_{\mathrm{u}}}[\hat{t}(f)-t(f)]^{2} B(f) d f,
$$

where $f_{\mathrm{u}}$ is the upper cutoff frequency and $B(f)$ represents the weight function calculated from amplitudes $A(f)$ at frequencies $f$. With reference to equation (6), phase derivation is linked to the amplitudes $A(2 \pi f)$, and the introduction of weight function facilitates the elimination of bias towards the formation of the curve of envelope delays. In addition, parameter constraints are required to ensure that the fitted parameters are within the physically defined limits, $\alpha$ is confined to $(0,-71]$ in this paper following a multitude trials; $f_{\text {corner }}$ is limited to $(0,15 \mathrm{~Hz}]$ in order to account for frequencies of interest.

2.2. Energy Ratio. The envelope delay describes the frequency component of the time evolution because of natural dispersion caused by surface waves. However, there is an existing problem associated with how the characteristics of later-arriving long-period components can be presented in the form of energy relative to high-frequency components. It is clear that geological effect, including basins or plains, accounts for amplifications of the long-period motions over long periods. Thus, the intensity of later-arriving surface waves can be estimated via the measurement of energy relative to the total energy of the motion.

Following this line, the later-arriving long-period amplitude $A_{1}$ should meet the following two criteria: (a) the frequency is less than the corner frequency $f_{\text {corner }}$ and (b) the corresponding value of arrival time $t(f)$ is greater than that of $t\left(f_{\text {corner }}\right)$. This means that later-arriving long-period amplitude $A_{1}$ is a function of the frequency $f$ and the arrival time $t(f)$. In order to illustrate this, the lower-right quadrant which is a representative of $A_{1}$ is marked in 

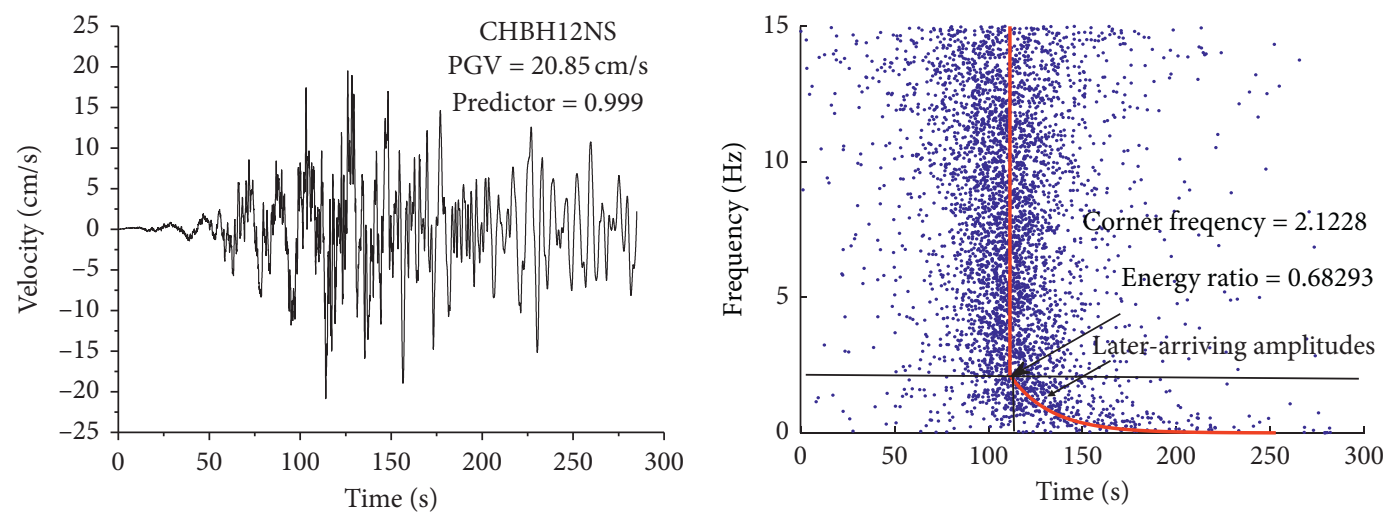

CHBH12NS from acceleration

Scatter points

— Fitted line

(a)

(b)
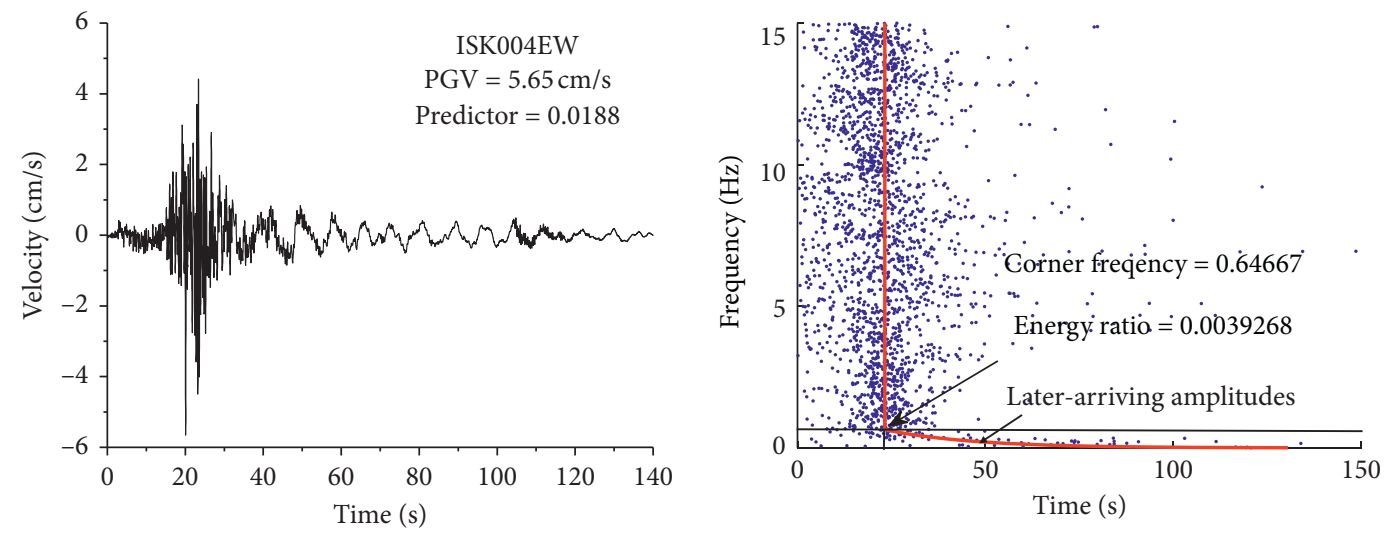

ISK004EW from acceleration

Scatter points

— Fitted line

(c)

(d)

Figure 3: Comparison of envelope delays for the identified long-period motion of CHBH12NS from Tohuku, M9, earthquake and nonlong-period motion of ISK004EW from Niigataken, Chuetsu-oki, M6.8, earthquake. The fitted line is derived by fitting the piecewise function to actual envelop delays in the sense of the least squares algorithm considering the weight function. (a) and (c) velocity-time series; (b) and (d) envelope delays including the fitted line. Note that the lower-right quadrant in (b) and (d) shows the later-arriving long-period amplitudes involved in the calculation of the energy ratio.

each of the figures related to envelope delays. The amplitudes $A_{1}$ for the later-arriving long-period components are written as

$$
A_{1}=A(t(f), f), \quad \text { for } f \text { and } t(f) \in\left\{\begin{array}{l}
0<f \leq f_{\text {corner }}, \\
t(f) \geq t\left(f_{\text {corner }}\right) .
\end{array}\right.
$$

Accordingly, the ratio of the sum of the squared amplitudes $A_{1}$, obtained from the later-arriving long-period components, to the total energy of the ground motion in the frequency content is defined as the energy ratio $E_{\text {ratio }}$ :

$$
E_{\text {ratio }}=\frac{\sum_{n} A_{1}^{2}}{\sum_{N} A(f)^{2}},
$$

where amplitudes $A(f)$ are derived from the Fourier transformation for a ground motion, $N$ is a representative of the total number of amplitudes of a ground motion in the frequency domain, and $n$ corresponds to the number of later-arriving long-period amplitudes $A_{1}$.

As shown in Figure 3(b), the lower-right quadrant indicates that the energy ratio $E_{\text {ratio }}$ for the recording $\mathrm{CHBH} 12 \mathrm{NS}$ is 0.683 , coupled with the corner frequency of $2.12 \mathrm{~Hz}$. In stark contrast, Figure $4(\mathrm{~d})$ indicates $E_{\text {ratio }}$ of ISK004EW at an extremely small value of 0.0039 , with its corner frequency equating to $0.64 \mathrm{~Hz}$. The large difference in energy ratios between the two records is consistent with the variations exhibited in velocity-time series. It is suggested from the comparison that the energy ratio $E_{\text {ratio }}$ provides an assessment of the intensity of the later-arriving long-period components relative to the ground motion in terms of energy. 


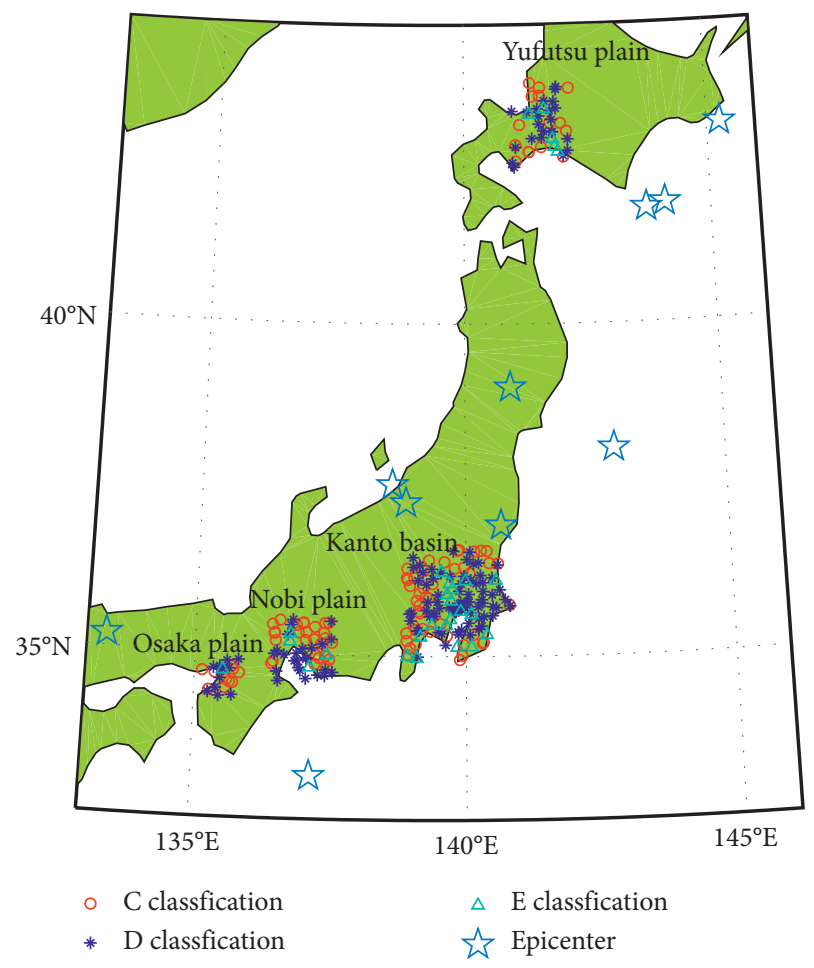

FIgUre 4: The map shows that stations belonging to K-NET and KiK-net strong networks, Japan, are distributed across Osaka plain, Nobi plain, Kanto basin, and Yufutsu plain, respectively, wherein geological conditions are likely to generate long-period motions; in terms of site classifications referring to the National Earthquake Hazard Reduction Program (NEHRP) standards, the stations are marked with circles, stars, and triangles to represent C, D, and E site classifications, respectively; pentagons represent the epicenter of each event.

\section{Ground Motions}

For the purpose of classifications, it is necessary to collect a database consisting of long-period and non-long-period ground motions. K-NET and KiK-net strong-motion networks are used herein as sources of long-period and nonlong-period ground motions.

Figure 4 shows a map linked to recording stations within either sedimentary basins or plains in Japan. It is known that K-NET and KiK-net strong-motion networks provide detailed information regarding these sites, wherein geological effects allow for the excitation of long-period motions. In light of this, the recording stations marked in Figure 4 were deliberately chosen on the basis of the provision of geological information (http://www.kyoshin.bosai.go.jp). This step improves the selection accuracy of long-period ground motions caused by geological effects. According to the guidelines of the NEHRP (National Earthquake Hazards Reduction Program), local site classifications are obtained after calculating $v_{30}$ (average shear-wave velocity of a profile up to $30 \mathrm{~m}$ ) for each site. In this regard, of approximately 267 checked stations which are distributed over the sedimentary sites in Figure 4, the numbers of soil conditions for C, D, and E are 98,141 , and 28, respectively.
The events which are of concern to seismologists and engineers $[2-4,23]$ reveal the fact that long-period ground motions enable long-period structures to excite resonant responses. In relation to this, the events with magnitudes greater than M6.5 and focal depths below $45 \mathrm{~km}$ are listed in Table 1, with each epicenter marked in Figure 4 . The premise for setting the minimum magnitude and depth is that large seismic magnitudes can maintain intensity significant enough to trigger substantial structural responses at distant sources and shallow events are prone to excite surface waves, which are amplified in deep sedimentary basins [24].

Besides, in order to further ensure the quality of individual records at long-period range and reduce variations as much as possible, certain limited conditions were also implemented as follows: (a) recordings with peak ground acceleration $P G A \geq 1.5 \mathrm{~cm} / \mathrm{s}_{2}$ were selected, and it is deemed that structures subjected to the recordings with such intensities may result in structural responses of interest. (b) In order to eliminate pulse-like motions, recording stations with hypocenter distances within $50 \mathrm{~km}$ were excluded $[6,12,25]$. (c) Horizontal histories were selected from recording instruments, which were either embedded in near surface layers or mounted in free fields, accounting for the presence of surface waves in close proximity to ground surface. (d) Selected histories should begin with either P or S waves in order to obtain sufficient duration containing surface waves. (e) Signal processing was employed by a band-pass filter between 0.05 and $25 \mathrm{~Hz}$.

It is possible that the multipeak envelope in accelerationtime histories results in a deviation in the determination of the parameters during the fitting process. This is due to the fact that the proposed model herein for envelope delays involves a two-piecewise function. For example, IBR001NS, Tohuku, M9, earthquake displays unusual envelope delays, as presented in Figure 5, these are primarily attributed to the successive occurrences of large fault ruptures [26]; the proposed model fails to accurately predict corresponding envelope delays. Thus, the exclusion of this type of the motions from the training dataset was performed in order to reduce error.

As a result, the number of records which meet the above requirements is 748 . Note that in consideration of complicated mechanisms varying from events, it is possible that the number of records for each station is unevenly distributed.

Furthermore, due to the lack of a quantitative definition of long-period motions, it is essential that we manually identified waveforms of the velocity-time series by means of visual inspection. A similar process was also carried out in works regarding identifications of pulse-like motions $[13,14,27]$. Accordingly, 264 records were manually classified as long-period motions against 484 non-long-period motions.

\section{Classification of Long-Period Ground Motions}

4.1. Criterion of Identification by Logistic Regression. This section is concerned with the establishment of a quantitative 
TABLE 1: Events used in the paper.

\begin{tabular}{lccccccc}
\hline Number & Date & Magnitude & Latitude & Longitude & Depth & Event index* & Event name or epicenter region \\
\hline 1 & 20001006 & 7.3 & 35.20 & 133.35 & 11 & 5 & Western Tottori prefecture \\
2 & 20030926 & 7.1 & 41.71 & 143.69 & 21 & 6 & Tokachi-oki \\
3 & 20030926 & 8 & 41.78 & 144.07 & 42 & 3 & Southeast of Kii peninsula \\
4 & 20040905 & 7.4 & 33.15 & 137.14 & 44 & 4 & Mid Niigata Prefecture \\
5 & 20041023 & 6.8 & 37.29 & 138.87 & 13 & 11 & Off Nemuro Peninsula \\
6 & 20041129 & 7.1 & 42.95 & 145.27 & 48 & 8 & The Niigataken Chuetsu-oki \\
7 & 20070716 & 6.8 & 37.56 & 138.61 & 17 & 9 & The Iwate-Miyagi Nairiku \\
8 & 20080614 & 7.2 & 39.03 & 140.88 & 8 & 10 & Tohuku \\
9 & 20110311 & 9 & 38.10 & 142.86 & 24 & 12 & Hamadori and Fukushima \\
10 & 20110311 & 7.4 & 38.10 & 142.86 & 24 & 2 & 7 \\
11 & 20110311 & 7.7 & 38.10 & 142.86 & 24 & 6 & \\
12 & 20110411 & 7 & 36.95 & 140.67 & & &
\end{tabular}

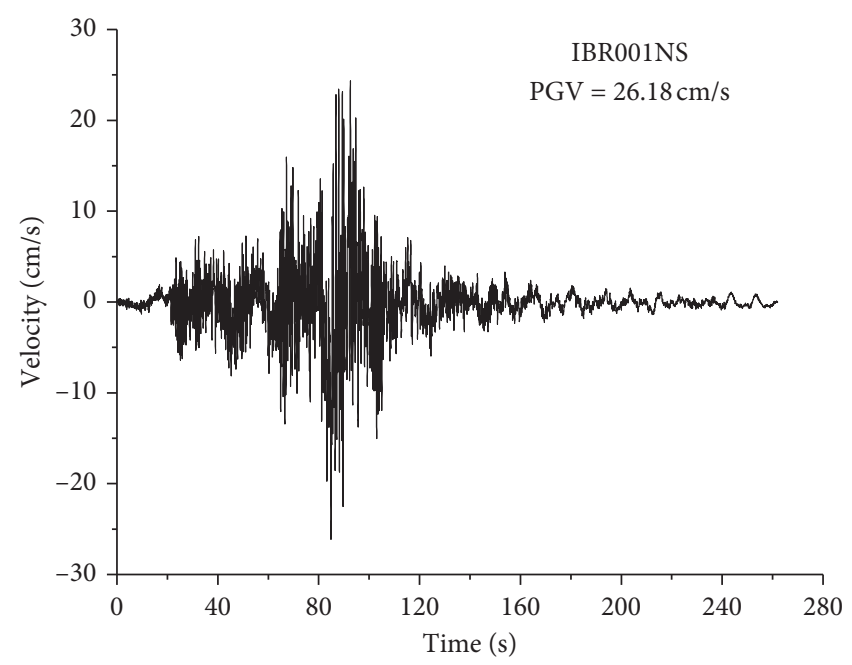

(a)

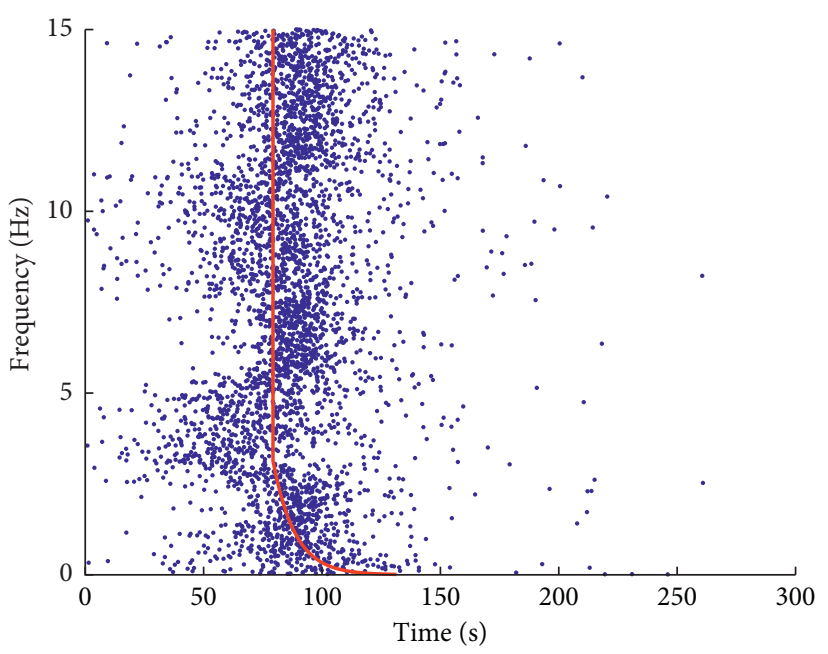

IBR001NS from acceleration

- Scatter points

— Fitted line

(b)

FIGURE 5: The record from IBR001NS, Tohuku, M9, earthquake shows that envelope delays coincide with the waveform in time series, resulting from three successive fault ruptures.

criterion, which aims to determine whether a given record is a long-period ground motion possessing sufficiently large amount of energy at frequencies below its corner frequency. Thus, two predictive variables including the energy ratio and the corner frequency are chosen, as they provide a quantitative assessment of long-period characteristics.

The works $[13,28]$ pertaining to the quantitative classification of pulse-like motions suggest that logistic regression [29] has the potential to enable the classification of long-period motions if we choose variables associated with its long-period characteristics. In this regard, the training dataset was built in the form of the corner frequency and the energy ratio for each candidate record, after performing manual classifications for long-period and non-long-period motions, respectively. As the result of binary classification implemented by SPSS software, the predictive formula is given as follows:

$$
\text { predictor }=\frac{1}{1+e^{-\left(-2.217-2.855 f_{\text {corner }}+27.936 E_{\text {ratio }}\right)}} \text {. }
$$

It is understood that this formula provides an estimation of the likelihood that a given record is a long-period motion on the basis of statistical theorem. Thus, the predictor takes values between 0 and 1 to assess the likelihood of a longperiod ground motion. In order to obtain the coefficients of the formula, we assign a threshold value, from which regression classifications should reproduce manual classifications as much as possible [13]. In view of this, the value of 0.8 is determined such that the regression results pertaining to the non-long-period motions are consistent with the manual classifications.

Consequently, a scatter plot of the predictive variables used for classifications is displayed in Figure 6, and the corresponding predictors for identified long-period ground 


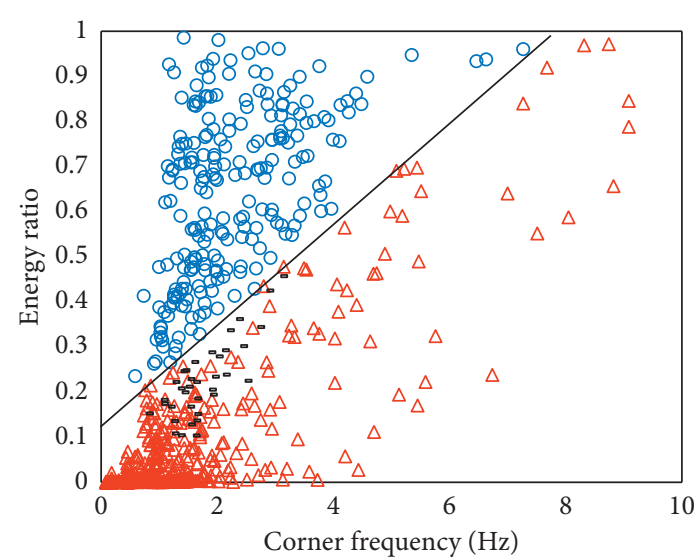

$$
\begin{aligned}
& \circ \text { Identified long-period ground motions } \\
& \Delta \text { Identified non-long-period ground motions } \\
& \text { - False positive records }
\end{aligned}
$$

FIGURE 6: Scatter plots of predictive variables of corner frequency and energy ratio for the classifications. Note that the representation of the false positive is manually classified as a long-period record but is identified as a non-long-period record by using the proposed method; the black line signifies the boundary to demarcate two discrete categories.

motions are listed in Table 2. The classification results from the predictor formula are listed in Table 3. Of the ground motions manually classified as long-period motions or nonlong-period motions, $95.2 \%$ were classified in the same manner by the formula and $4.8 \%$ were misclassified. Furthermore, it is found that about $86.4 \%$ (228 out of 264) were labelled as long-period motions and approximately $100 \%$ (484 out of 484) remained classified as non-long-period motions. In view of the fact that two discrete classifications were determined by continuous predictors, it is possible that, in some areas, there is an occurrence of overlap between long-period ground motions and non-long-period ground motions. As inferred from Figure 6, the records whose initial long-period classifications were not reproduced by the formula are distributed along the border (the black line in Figure 6). However, we can assume from the plot that if a ground motion has a high energy ratio coupled with a low corner frequency, the likelihood of identifying a long-period motion increases significantly.

Figure 7 shows the distribution of identified long-period ground motions with respect to site classifications and epicentral distances. Of the 228 records which are identified as the long-period ground motions by the predictor formula, the numbers for C, D, and E sites are 52, 129, and 47, respectively. In addition, the records with epicentral distances between 100 and $300 \mathrm{~km}$ are very available; however, beyond this range, records are mostly from Tohuku, M9, earthquake, with mostly clustered distances between 400 and $500 \mathrm{~km}$. It is deemed that effects of long-period ground motions during megaearthquakes could not be ignored even if epicenter distances exceed $500 \mathrm{~km}$ [30]. In this regard, it is noteworthy that such long-period ground motions are not often incorporated into the design spectrum for high-rise buildings [31] because engineering designs are driven by the expected magnitude of the earthquake and the distance to near faults. Therefore, it is recommended that the influence of longperiod motions triggered by large faults on long-period structures at distant sedimentary sites should be taken into serious consideration.

4.2. Analysis of Classification Results. In order to estimate the effectiveness of the proposed method for the identification of the long-period motions, the examinations pertaining to discrepancy are performed in some cases, in which a manual review of long-period motions was not reproduced by using the proposed method.

The process pertaining to the truncation of a portion which is mainly composed of later-arriving amplitudes is detailed in the following, as is similar to the studies $[5,15,32]$. Firstly, in the context of phase dispersion, the portion of a record is truncated from its complete record later than its an arrival time $t\left(f_{\text {corner }}\right)$; besides, a filter with a high-cut frequency of $f_{\text {corner }}$, as suggested by Boore [15] used for processing strong motions, is employed in order to remove the components with frequencies larger than the corner frequency $f_{\text {corner }}$ (in essence, this possibly removes body waves). The aforementioned two steps ensure that the later-arriving long-period amplitudes are in the presence of a truncated wave, thus allowing the examination whether the identified long-period motions are in accordance with the anticipated features.

Figure 8 shows six samples (positive records) of longperiod motions which are identified by using the proposed method. Each sample has three subplots, including a velocity-time series, a velocity response spectrum, and envelope delay. Generally, it is seen that the truncated waves play a dominant role in determining broadband long-period characteristics of long-period ground motions as the whole, as each velocity spectrum of the truncated waves is consistent with the corresponding spectrum of the complete records over longer periods larger than $2 \mathrm{sec}$. Broadband long-period characteristics indicate that the later-arriving waves appear to be dispersive, accounting for multiple dominant periods in each velocity spectrum.

On the contrary, five samples (false positive records) whose long-period characteristics were not reproduced by using the proposed method are illustrated in Figure 9. In view of causation of the discrepancy, the five samples are separated into two groups. The first group contains the former three samples, as seen in Figures 9(a)-9(c). It is observed from their velocity spectrum that these records are almost characterized as the narrowband properties. This indicates that their long-period characteristics are dependent upon one or two dominant periods, in opposition to broadband long-period characteristics shown in Figure 8. In order to illustrate variations pertaining to mechanisms, the process of obtaining a truncated wave differs from that used in positive records (described above). Specifically, the portion of each record is truncated prior to its arrival time $t\left(f_{\text {corner }}\right)$, as is marked with red dashed lines in velocity-time series shown in the first three plots. It is found that the truncated waves, consisting of early arrival amplitudes, 
TABLE 2: Records identified as long-period ground motions by using the proposed method.

\begin{tabular}{|c|c|c|c|c|c|c|}
\hline Station & Corner frequency & Energy ratio & Predictor & Event index* & Epicentral distance & Site \\
\hline OSKH02NS & 3.065265 & 0.962228 & 1 & 5 & 198.793 & $\mathrm{C}$ \\
\hline OSKH02EW & 2.794872 & 0.951052 & 1 & 5 & 198.793 & $\mathrm{C}$ \\
\hline OSK003EW & 3.7625 & 0.898807 & 0.999995 & 5 & 201.903 & $\mathrm{D}$ \\
\hline OSK003NS & 3.584838 & 0.879794 & 0.999995 & 5 & 201.903 & $\mathrm{D}$ \\
\hline HYG022EW & 0.807795 & 0.413461 & 0.999113 & 5 & 192.264 & $\mathrm{D}$ \\
\hline IKRH03NS & 2.531998 & 0.413425 & 0.891252 & 6 & 213.833 & $\mathrm{D}$ \\
\hline IKRH03EW & 3.498246 & 0.550984 & 0.960373 & 6 & 213.833 & $\mathrm{D}$ \\
\hline IKRH02EW & 1.963153 & 0.376051 & 0.936049 & 6 & 237.185 & $\mathrm{E}$ \\
\hline HKD118EW & 3.243775 & 0.759182 & 0.999941 & 6 & 251.084 & $\mathrm{D}$ \\
\hline HKD178EW & 3.147187 & 0.861797 & 0.999997 & 6 & 254.792 & $\mathrm{D}$ \\
\hline HKD178NS & 2.742523 & 0.84731 & 0.999999 & 6 & 254.792 & $\mathrm{D}$ \\
\hline AOM021EW & 2.390755 & 0.538594 & 0.997536 & 6 & 241.254 & $\mathrm{D}$ \\
\hline IBUH05NS & 2.542374 & 0.681667 & 0.99993 & 3 & 241.261 & $\mathrm{C}$ \\
\hline IBUH05EW & 2.162977 & 0.700304 & 0.999986 & 3 & 241.261 & $\mathrm{C}$ \\
\hline IKRH03NS & 4.135434 & 0.922407 & 0.999992 & 3 & 235.28 & $\mathrm{D}$ \\
\hline IKRH02NS & 1.764912 & 0.75246 & 0.999999 & 3 & 255.304 & $\mathrm{E}$ \\
\hline IKRH02EW & 7.294737 & 0.93734 & 0.958595 & 3 & 255.304 & $\mathrm{E}$ \\
\hline HKD105NS & 1.004252 & 0.263015 & 0.905805 & 3 & 184.266 & $\mathrm{C}$ \\
\hline HKD129EW & 4.537566 & 0.83678 & 0.999727 & 3 & 224.786 & $\mathrm{C}$ \\
\hline HKD129NS & 1.916364 & 0.668818 & 0.999983 & 3 & 224.786 & $\mathrm{C}$ \\
\hline HKD130EW & 2.148647 & 0.725926 & 0.999993 & 3 & 241.238 & $\mathrm{C}$ \\
\hline HKD130NS & 3.236714 & 0.75985 & 0.999943 & 3 & 241.238 & $\mathrm{C}$ \\
\hline HKD120EW & 4.230392 & 0.8097 & 0.999758 & 3 & 263.301 & $\mathrm{D}$ \\
\hline HKD120NS & 4.664289 & 0.84516 & 0.999689 & 3 & 263.301 & $\mathrm{D}$ \\
\hline HKD122NS & 3.154127 & 0.838083 & 0.999995 & 3 & 245.84 & $\mathrm{D}$ \\
\hline HKD178EW & 5.886054 & 0.94734 & 0.999415 & 3 & 275.181 & $\mathrm{D}$ \\
\hline HKD178NS & 3.367404 & 0.96083 & 1 & 3 & 275.181 & $\mathrm{D}$ \\
\hline HKD179NS & 3.00411 & 0.868665 & 0.999999 & 3 & 264.276 & $\mathrm{D}$ \\
\hline HKD179EW & 3.44 & 0.83873 & 0.999989 & 3 & 264.276 & $\mathrm{D}$ \\
\hline HKD181NS & 1.596639 & 0.389663 & 0.98386 & 3 & 255.399 & $\mathrm{D}$ \\
\hline HKD182NS & 2.082714 & 0.571818 & 0.999595 & 3 & 247.424 & $\mathrm{D}$ \\
\hline HKD180EW & 3.898436 & 0.84414 & 0.999964 & 3 & 269.99 & $\mathrm{E}$ \\
\hline HKD084NS & 2.37715 & 0.472772 & 0.985278 & 3 & 148.138 & $\mathrm{C}$ \\
\hline CHBH10NS & 1.287612 & 0.92678 & 1 & 4 & 390.291 & $\mathrm{D}$ \\
\hline CHBH10EW & 1.565669 & 0.98607 & 1 & 4 & 390.291 & $\mathrm{D}$ \\
\hline OSK007EW & 2.648446 & 0.478623 & 0.973208 & 4 & 211.303 & $\mathrm{C}$ \\
\hline HYG022NS & 2.635287 & 0.466258 & 0.963898 & 4 & 242.606 & $\mathrm{D}$ \\
\hline MIE003NS & 2.712927 & 0.566378 & 0.997157 & 4 & 207.634 & $\mathrm{D}$ \\
\hline OSK006EW & 2.212204 & 0.491778 & 0.994544 & 4 & 222.371 & $\mathrm{D}$ \\
\hline OSK006NS & 3.239262 & 0.604658 & 0.995621 & 4 & 222.371 & $\mathrm{D}$ \\
\hline OSK008NS & 1.272093 & 0.368782 & 0.988496 & 4 & 216.864 & $\mathrm{D}$ \\
\hline AIC003EW & 1.721421 & 0.719596 & 0.999998 & 4 & 227.851 & $\mathrm{E}$ \\
\hline MYG005NS & 2 & 0.770263 & 0.999999 & 11 & 229.204 & $\mathrm{D}$ \\
\hline NGN015EW & 1.354651 & 0.693799 & 0.999998 & 11 & 153.839 & $\mathrm{D}$ \\
\hline MYG017EW & 3.72093 & 0.768698 & 0.999822 & 11 & 185.336 & $\mathrm{E}$ \\
\hline ISK002EW & 1.473684 & 0.320931 & 0.926977 & 11 & 140.925 & $\mathrm{E}$ \\
\hline ISK002NS & 1.964912 & 0.397348 & 0.963508 & 11 & 140.925 & $\mathrm{E}$ \\
\hline FKS024EW & 2.859375 & 0.539519 & 0.99091 & 11 & 112.735 & $\mathrm{D}$ \\
\hline FKS024NS & 4.172507 & 0.601316 & 0.935164 & 11 & 112.735 & $\mathrm{D}$ \\
\hline IKRH02NS & 2.131996 & 0.782818 & 0.999999 & 8 & 296.466 & $\mathrm{E}$ \\
\hline HKD126NS & 2.673077 & 0.543681 & 0.995225 & 8 & 276.965 & $\mathrm{E}$ \\
\hline IBRH10EW & 1.158154 & 0.315132 & 0.963736 & 9 & 202.274 & $\mathrm{E}$ \\
\hline TCG012NS & 1.255624 & 0.482176 & 0.999533 & 9 & 176.825 & $\mathrm{C}$ \\
\hline SIT003EW & 1.813519 & 0.880533 & 1 & 9 & 191.297 & $\mathrm{E}$ \\
\hline SIT003NS & 2.043108 & 0.897758 & 1 & 9 & 191.297 & $\mathrm{E}$ \\
\hline SIT010NS & 1.504256 & 0.590451 & 0.999954 & 9 & 205.371 & $\mathrm{E}$ \\
\hline NGN008EW & 1.29054 & 0.675453 & 0.999998 & 9 & 132.08 & $\mathrm{C}$ \\
\hline NGN008NS & 1.950835 & 0.676695 & 0.999985 & 9 & 132.08 & $\mathrm{C}$ \\
\hline NGN015EW & 1.319473 & 0.623768 & 0.999989 & 9 & 173.498 & $\mathrm{D}$ \\
\hline NGN015NS & 1.267456 & 0.700939 & 0.999999 & 9 & 173.498 & $\mathrm{D}$ \\
\hline
\end{tabular}


TABle 2: Continued.

\begin{tabular}{|c|c|c|c|c|c|c|}
\hline Station & Corner frequency & Energy ratio & Predictor & Event index* & Epicentral distance & Site \\
\hline ISK007EW & 1.938776 & 0.725381 & 0.999996 & 9 & 156.195 & $E$ \\
\hline ISK007NS & 2.963141 & 0.693727 & 0.999834 & 9 & 156.195 & $\mathrm{E}$ \\
\hline FKS020EW & 1.584589 & 0.504865 & 0.999366 & 9 & 132.531 & $\mathrm{E}$ \\
\hline FKS020NS & 1.040875 & 0.26812 & 0.909001 & 9 & 132.531 & $\mathrm{E}$ \\
\hline YMT011NS & 2.015038 & 0.548924 & 0.999367 & 9 & 160.191 & $\mathrm{D}$ \\
\hline YMT001EW & 1.589615 & 0.707671 & 0.999998 & 10 & 93.3553 & $\mathrm{D}$ \\
\hline YMT001NS & 2.768261 & 0.832274 & 0.999998 & 10 & 93.3553 & $\mathrm{D}$ \\
\hline MYG006EW & 1.139153 & 0.342084 & 0.983491 & 10 & 50.2725 & $\mathrm{E}$ \\
\hline MYG006NS & 1.312281 & 0.389482 & 0.992732 & 10 & 50.2725 & $\mathrm{E}$ \\
\hline YMT003NS & 2.938272 & 0.473791 & 0.932772 & 10 & 99.3062 & $\mathrm{C}$ \\
\hline MYGH06NS & 1.407018 & 0.28582 & 0.852034 & 10 & 51.3019 & $\mathrm{C}$ \\
\hline OSKH02NS & 1.353383 & 0.690987 & 0.999998 & 2 & 557.279 & $\mathrm{C}$ \\
\hline OSKH02EW & 2.451128 & 0.935847 & 1 & 2 & 557.279 & $\mathrm{C}$ \\
\hline CHB021EW & 3.237864 & 0.714614 & 0.999797 & 2 & 181.927 & $\mathrm{C}$ \\
\hline CHB021NS & 3.825243 & 0.721417 & 0.999103 & 2 & 181.927 & $\mathrm{C}$ \\
\hline CHB025EW & 1.519298 & 0.663825 & 0.999994 & 2 & 173.869 & $\mathrm{C}$ \\
\hline CHB025NS & 2.333333 & 0.704789 & 0.99998 & 2 & 173.869 & $\mathrm{C}$ \\
\hline KNG003NS & 3.676923 & 0.710547 & 0.999204 & 2 & 172.478 & $\mathrm{C}$ \\
\hline KNG006EW & 3.333333 & 0.575414 & 0.987145 & 2 & 172.1 & $\mathrm{C}$ \\
\hline KNG006NS & 2.287719 & 0.555255 & 0.998846 & 2 & 172.1 & $\mathrm{C}$ \\
\hline KNG010EW & 4.522807 & 0.756306 & 0.997524 & 2 & 193.271 & $\mathrm{C}$ \\
\hline KNG010NS & 2.161403 & 0.674097 & 0.999971 & 2 & 193.271 & $\mathrm{C}$ \\
\hline CHB013NS & 4.245614 & 0.667207 & 0.986625 & 2 & 115.667 & $\mathrm{D}$ \\
\hline CHB015NS & 3.912281 & 0.723435 & 0.998913 & 2 & 146.725 & $\mathrm{D}$ \\
\hline CHB022EW & 3.621053 & 0.548463 & 0.940853 & 2 & 155.056 & $\mathrm{D}$ \\
\hline CHB022NS & 3.768421 & 0.590598 & 0.971338 & 2 & 155.056 & $\mathrm{D}$ \\
\hline CHB026EW & 1.105263 & 0.387951 & 0.995787 & 2 & 122.644 & $\mathrm{D}$ \\
\hline CHB026NS & 0.650485 & 0.235401 & 0.924283 & 2 & 122.644 & $\mathrm{D}$ \\
\hline KNG004EW & 3.010648 & 0.519092 & 0.975612 & 2 & 183.284 & $\mathrm{D}$ \\
\hline KNG004NS & 4.364912 & 0.606067 & 0.904846 & 2 & 183.284 & $\mathrm{D}$ \\
\hline SIT002EW & 2.94386 & 0.564152 & 0.994167 & 2 & 168.982 & $\mathrm{D}$ \\
\hline SIT013NS & 4.129825 & 0.657487 & 0.987382 & 2 & 165.948 & $\mathrm{D}$ \\
\hline TKY004NS & 2.066667 & 0.445042 & 0.986815 & 2 & 176.351 & $\mathrm{D}$ \\
\hline TKY006EW & 3.850187 & 0.61839 & 0.983144 & 2 & 165.415 & $\mathrm{D}$ \\
\hline TKY018EW & 1.567884 & 0.444199 & 0.996717 & 2 & 140.538 & $\mathrm{D}$ \\
\hline TKY018NS & 2.149701 & 0.503016 & 0.996658 & 2 & 140.538 & $\mathrm{D}$ \\
\hline TKY024EW & 1.392982 & 0.410186 & 0.994857 & 2 & 133.002 & $\mathrm{D}$ \\
\hline TKY024NS & 1.854539 & 0.435163 & 0.990482 & 2 & 133.002 & $\mathrm{D}$ \\
\hline TKY027NS & 1.128727 & 0.345737 & 0.9855 & 2 & 132.309 & $\mathrm{D}$ \\
\hline CHB009EW & 1.382456 & 0.409147 & 0.994862 & 2 & 118.77 & $\mathrm{E}$ \\
\hline CHB009NS & 1.416979 & 0.302 & 0.897909 & 2 & 118.77 & $\mathrm{E}$ \\
\hline KNG001EW & 2.636889 & 0.583577 & 0.998583 & 2 & 154.819 & $\mathrm{E}$ \\
\hline KNG001NS & 2.691404 & 0.588471 & 0.998556 & 2 & 154.819 & $\mathrm{E}$ \\
\hline KNG013EW & 4.695652 & 0.820325 & 0.999321 & 2 & 212.95 & $\mathrm{E}$ \\
\hline KNG013NS & 3.89372 & 0.79685 & 0.999867 & 2 & 212.95 & $\mathrm{E}$ \\
\hline SIT008EW & 1.891228 & 0.421265 & 0.984511 & 2 & 137.094 & $\mathrm{E}$ \\
\hline SIT011NS & 1.179359 & 0.300462 & 0.943195 & 2 & 143.142 & $\mathrm{E}$ \\
\hline TKY005NS & 3.670175 & 0.568949 & 0.96079 & 2 & 177.114 & $\mathrm{D}$ \\
\hline CHBH11NS & 4.831579 & 0.861686 & 0.999684 & 1 & 395.179 & $\mathrm{C}$ \\
\hline CHBH11EW & 7.110088 & 0.933592 & 0.972469 & 1 & 395.179 & $\mathrm{C}$ \\
\hline CHBH16NS & 2.62807 & 0.71005 & 0.99996 & 1 & 418.631 & $\mathrm{C}$ \\
\hline CHBH16EW & 2.887174 & 0.745081 & 0.999968 & 1 & 418.631 & $\mathrm{C}$ \\
\hline CHBH17NS & 2.727915 & 0.685353 & 0.999893 & 1 & 395.73 & $\mathrm{C}$ \\
\hline IBUH02NS & 3.220167 & 0.81326 & 0.999988 & 1 & 533.116 & $\mathrm{C}$ \\
\hline IBUH02EW & 4.933333 & 0.838239 & 0.999188 & 1 & 533.116 & $\mathrm{C}$ \\
\hline IBUH05NS & 1.854964 & 0.842197 & 1 & 1 & 511.566 & $\mathrm{C}$ \\
\hline IBUH05EW & 2.187998 & 0.858736 & 1 & 1 & 511.566 & $\mathrm{C}$ \\
\hline OSKH02NS & 2.223485 & 0.980296 & 1 & 1 & 770.997 & $\mathrm{C}$ \\
\hline OSKH02EW & 1.386364 & 0.909078 & 1 & 1 & 770.997 & $\mathrm{C}$ \\
\hline CHBH10NS & 3.05614 & 0.604811 & 0.997411 & 1 & 367.521 & $\mathrm{D}$ \\
\hline
\end{tabular}


TABle 2: Continued.

\begin{tabular}{|c|c|c|c|c|c|c|}
\hline Station & Corner frequency & Energy ratio & Predictor & Event index* & Epicentral distance & Site \\
\hline CHBH10EW & 3.226368 & 0.592912 & 0.994149 & 1 & 367.521 & $\mathrm{D}$ \\
\hline CHBH12NS & 3.393807 & 0.762432 & 0.999917 & 1 & 407.073 & $\mathrm{D}$ \\
\hline CHBH12EW & 2.122807 & 0.682929 & 0.99998 & 1 & 407.073 & $\mathrm{D}$ \\
\hline IBRH20NS & 1.870113 & 0.328554 & 0.835114 & 1 & 315.605 & $\mathrm{D}$ \\
\hline IBRH20EW & 3.420712 & 0.570071 & 0.980967 & 1 & 315.605 & $\mathrm{D}$ \\
\hline IKRH03NS & 1.536842 & 0.750714 & 0.999999 & 1 & 541.302 & $\mathrm{D}$ \\
\hline IKRH03EW & 1.463603 & 0.727768 & 0.999999 & 1 & 541.302 & $\mathrm{D}$ \\
\hline SRCH07EW & 4.312281 & 0.802902 & 0.99963 & 1 & 575.113 & $\mathrm{D}$ \\
\hline SRCH09NS & 1.961404 & 0.595798 & 0.999853 & 1 & 557.48 & $\mathrm{D}$ \\
\hline IKRH02NS & 2.080702 & 0.854545 & 1 & 1 & 577.359 & $\mathrm{E}$ \\
\hline IKRH02EW & 1.735189 & 0.709653 & 0.999997 & 1 & 577.359 & $\mathrm{E}$ \\
\hline CHB021EW & 2.188923 & 0.469424 & 0.990505 & 1 & 442.763 & $\mathrm{C}$ \\
\hline CHB021NS & 2.308772 & 0.550751 & 0.99861 & 1 & 442.763 & $\mathrm{C}$ \\
\hline CHB025EW & 2.649123 & 0.794705 & 0.999996 & 1 & 434.585 & $\mathrm{C}$ \\
\hline CHB025NS & 3.470175 & 0.865441 & 0.999994 & 1 & 434.585 & $\mathrm{C}$ \\
\hline HKD105EW & 1.101754 & 0.477341 & 0.999655 & 1 & 491.096 & $\mathrm{C}$ \\
\hline HKD105NS & 1.889815 & 0.651899 & 0.999975 & 1 & 491.096 & $\mathrm{C}$ \\
\hline HKD123EW & 1.473896 & 0.743897 & 0.999999 & 1 & 547.805 & $\mathrm{C}$ \\
\hline HKD124EW & 2.431579 & 0.804728 & 0.999998 & 1 & 551.117 & $\mathrm{C}$ \\
\hline HKD124NS & 1.50262 & 0.765818 & 1 & 1 & 551.117 & $\mathrm{C}$ \\
\hline HKD129EW & 1.216549 & 0.62081 & 0.999991 & 1 & 514.31 & $\mathrm{C}$ \\
\hline HKD129NS & 1.605898 & 0.75124 & 0.999999 & 1 & 514.31 & $\mathrm{C}$ \\
\hline HKD130EW & 1.975566 & 0.855551 & 1 & 1 & 511.54 & $\mathrm{C}$ \\
\hline HKD130NS & 1.757895 & 0.836844 & 1 & 1 & 511.54 & $\mathrm{C}$ \\
\hline CHB010NS & 3.209241 & 0.497645 & 0.925727 & 1 & 335.212 & $\mathrm{D}$ \\
\hline CHB011EW & 1.796491 & 0.494016 & 0.99843 & 1 & 348.212 & $\mathrm{D}$ \\
\hline CHB011NS & 1.127699 & 0.331835 & 0.978826 & 1 & 348.212 & $\mathrm{D}$ \\
\hline CHB012EW & 4.157895 & 0.637149 & 0.976144 & 1 & 360.028 & $\mathrm{D}$ \\
\hline CHB013EW & 3.445614 & 0.763533 & 0.999906 & 1 & 374.717 & $\mathrm{D}$ \\
\hline CHB013NS & 3.585965 & 0.793631 & 0.99994 & 1 & 374.717 & $\mathrm{D}$ \\
\hline CHB014EW & 3.02807 & 0.696236 & 0.999814 & 1 & 384.514 & $\mathrm{D}$ \\
\hline CHB014NS & 3.09761 & 0.674593 & 0.999584 & 1 & 384.514 & $\mathrm{D}$ \\
\hline CHB015EW & 2.431765 & 0.779265 & 0.999997 & 1 & 401.04 & $\mathrm{D}$ \\
\hline CHB015NS & 2.354386 & 0.744282 & 0.999993 & 1 & 401.04 & $\mathrm{D}$ \\
\hline CHB017EW & 4.038596 & 0.800491 & 0.999819 & 1 & 398.387 & $\mathrm{D}$ \\
\hline CHB017NS & 3.395686 & 0.768526 & 0.999929 & 1 & 398.387 & $\mathrm{D}$ \\
\hline CHB024EW & 1.385965 & 0.416177 & 0.995732 & 1 & 369.581 & $\mathrm{D}$ \\
\hline CHB024NS & 1.441063 & 0.496147 & 0.999463 & 1 & 369.581 & $\mathrm{D}$ \\
\hline CHB026EW & 3.54386 & 0.753335 & 0.999835 & 1 & 381.673 & $\mathrm{D}$ \\
\hline CHB026NS & 2.975439 & 0.692273 & 0.999821 & 1 & 381.673 & $\mathrm{D}$ \\
\hline CHB029EW & 1.905263 & 0.56678 & 0.999719 & 1 & 374.398 & $\mathrm{D}$ \\
\hline CHB029NS & 1.785965 & 0.559095 & 0.999752 & 1 & 374.398 & $\mathrm{D}$ \\
\hline HKD104EW & 3.410909 & 0.778206 & 0.999944 & 1 & 501.917 & $\mathrm{D}$ \\
\hline HKD104NS & 1.694107 & 0.70963 & 0.999997 & 1 & 501.917 & $\mathrm{D}$ \\
\hline HKD118EW & 2.922807 & 0.910892 & 1 & 1 & 610.347 & $\mathrm{D}$ \\
\hline HKD118NS & 3.133333 & 0.905301 & 0.999999 & 1 & 610.347 & $\mathrm{D}$ \\
\hline HKD120EW & 2.266667 & 0.759994 & 0.999996 & 1 & 590.733 & $\mathrm{D}$ \\
\hline HKD120NS & 1.975439 & 0.765163 & 0.999999 & 1 & 590.733 & $\mathrm{D}$ \\
\hline HKD122EW & 1.49986 & 0.705809 & 0.999998 & 1 & 573.027 & $\mathrm{D}$ \\
\hline HKD122NS & 2.038596 & 0.805595 & 0.999999 & 1 & 573.027 & $\mathrm{D}$ \\
\hline HKD125EW & 1.308772 & 0.26605 & 0.814396 & 1 & 520.86 & $\mathrm{D}$ \\
\hline HKD127NS & 1.708772 & 0.33937 & 0.915685 & 1 & 537.071 & $\mathrm{D}$ \\
\hline HKD178EW & 2.124129 & 0.939097 & 1 & 1 & 578.05 & $\mathrm{D}$ \\
\hline HKD178NS & 1.915789 & 0.91936 & 1 & 1 & 578.05 & $\mathrm{D}$ \\
\hline HKD179EW & 2.013647 & 0.855838 & 1 & 1 & 579.845 & $\mathrm{D}$ \\
\hline HKD179NS & 1.789474 & 0.844169 & 1 & 1 & 579.845 & $\mathrm{D}$ \\
\hline HKD181EW & 2.2 & 0.670171 & 0.999964 & 1 & 567.66 & $\mathrm{D}$ \\
\hline HKD181NS & 1.880702 & 0.690111 & 0.999992 & 1 & 567.66 & $\mathrm{D}$ \\
\hline HKD184NS & 2.312281 & 0.585622 & 0.99947 & 1 & 531.287 & $\mathrm{D}$ \\
\hline IBR009EW & 2.321031 & 0.455798 & 0.979957 & 1 & 352.031 & $\mathrm{D}$ \\
\hline
\end{tabular}


TABLE 2: Continued.

\begin{tabular}{|c|c|c|c|c|c|c|}
\hline Station & Corner frequency & Energy ratio & Predictor & Event index* & Epicentral distance & Site \\
\hline MIE003EW & 1.796491 & 0.83436 & 1 & 1 & 656.657 & $\mathrm{D}$ \\
\hline MIE003NS & 2.42807 & 0.905403 & 1 & 1 & 656.657 & $\mathrm{D}$ \\
\hline TKY004NS & 1.86751 & 0.369329 & 0.940968 & 1 & 412.767 & $\mathrm{D}$ \\
\hline TKY006EW & 2.182456 & 0.466853 & 0.98999 & 1 & 400.819 & $\mathrm{D}$ \\
\hline TKY006NS & 1.721864 & 0.365181 & 0.955586 & 1 & 400.819 & $\mathrm{D}$ \\
\hline TKY014EW & 1.369994 & 0.397631 & 0.993172 & 1 & 380.016 & $\mathrm{D}$ \\
\hline TKY014NS & 1.700919 & 0.47077 & 0.997713 & 1 & 380.016 & $\mathrm{D}$ \\
\hline TKY015NS & 1.575439 & 0.475721 & 0.998607 & 1 & 378.158 & $\mathrm{D}$ \\
\hline TKY017EW & 2.140351 & 0.719307 & 0.999992 & 1 & 384.974 & $\mathrm{D}$ \\
\hline TKY018EW & 1.13859 & 0.322171 & 0.971598 & 1 & 384.221 & $\mathrm{D}$ \\
\hline TKY018NS & 1.95614 & 0.483616 & 0.996693 & 1 & 384.221 & $\mathrm{D}$ \\
\hline TKY020EW & 1.054625 & 0.316188 & 0.973534 & 1 & 383.554 & $\mathrm{D}$ \\
\hline TKY020NS & 1.415732 & 0.427397 & 0.996601 & 1 & 383.554 & $\mathrm{D}$ \\
\hline TKY021EW & 1.529825 & 0.392021 & 0.987468 & 1 & 381.146 & $\mathrm{D}$ \\
\hline TKY021NS & 1.957161 & 0.533594 & 0.999177 & 1 & 381.146 & $\mathrm{D}$ \\
\hline TKY022EW & 1.708164 & 0.489179 & 0.998603 & 1 & 382.628 & $\mathrm{D}$ \\
\hline TKY022NS & 1.53564 & 0.428744 & 0.995396 & 1 & 382.628 & $\mathrm{D}$ \\
\hline TKY023EW & 1.996195 & 0.643158 & 0.999957 & 1 & 377.804 & $\mathrm{D}$ \\
\hline TKY023NS & 1.767858 & 0.564148 & 0.999796 & 1 & 377.804 & $\mathrm{D}$ \\
\hline TKY024EW & 1.62807 & 0.405656 & 0.988652 & 1 & 374.258 & $\mathrm{D}$ \\
\hline TKY024NS & 1.97193 & 0.470299 & 0.994991 & 1 & 374.258 & $\mathrm{D}$ \\
\hline TKY025EW & 2.205766 & 0.385362 & 0.904739 & 1 & 374.153 & $\mathrm{D}$ \\
\hline TKY025NS & 2.208975 & 0.450458 & 0.98305 & 1 & 374.153 & $\mathrm{D}$ \\
\hline TKY026EW & 1.498246 & 0.419007 & 0.994573 & 1 & 379.731 & $\mathrm{D}$ \\
\hline TKY026NS & 1.451875 & 0.411554 & 0.994148 & 1 & 379.731 & $\mathrm{D}$ \\
\hline TKY027EW & 1.607018 & 0.429112 & 0.994418 & 1 & 376.218 & $\mathrm{D}$ \\
\hline TKY027NS & 1.715789 & 0.56087 & 0.999807 & 1 & 376.218 & $\mathrm{D}$ \\
\hline AIC003EW & 1.528369 & 0.85293 & 1 & 1 & 636.358 & $\mathrm{E}$ \\
\hline AIC003NS & 2.014184 & 0.924111 & 1 & 1 & 636.358 & $\mathrm{E}$ \\
\hline CHB009EW & 1.715142 & 0.471503 & 0.997667 & 1 & 370.281 & $\mathrm{E}$ \\
\hline CHB016EW & 3.414035 & 0.813846 & 0.999979 & 1 & 381.548 & $\mathrm{E}$ \\
\hline CHB016NS & 3.438596 & 0.835989 & 0.999988 & 1 & 381.548 & $\mathrm{E}$ \\
\hline CHB019EW & 3.766378 & 0.816508 & 0.999947 & 1 & 428.331 & $\mathrm{E}$ \\
\hline CHB019NS & 5.045614 & 0.898911 & 0.999794 & 1 & 428.331 & $\mathrm{E}$ \\
\hline CHB020EW & 3.635088 & 0.828468 & 0.999974 & 1 & 413.209 & $\mathrm{E}$ \\
\hline CHB020NS & 2.965497 & 0.755643 & 0.99997 & 1 & 413.209 & $\mathrm{E}$ \\
\hline HKD126EW & 1.922319 & 0.503054 & 0.998253 & 1 & 502.843 & $\mathrm{E}$ \\
\hline HKD128EW & 3.561224 & 0.673822 & 0.998406 & 1 & 525.162 & $\mathrm{E}$ \\
\hline HKD128NS & 3.140351 & 0.697492 & 0.999752 & 1 & 525.162 & $\mathrm{E}$ \\
\hline SIT003EW & 1.20185 & 0.377561 & 0.992603 & 1 & 360.375 & $\mathrm{E}$ \\
\hline SIT003NS & 1.849123 & 0.546571 & 0.999579 & 1 & 360.375 & $\mathrm{E}$ \\
\hline SIT008EW & 1.775439 & 0.498947 & 0.998711 & 1 & 363.587 & $\mathrm{E}$ \\
\hline SIT010EW & 1.759152 & 0.476904 & 0.997725 & 1 & 375.649 & $\mathrm{E}$ \\
\hline YMT003NS & 4.392982 & 0.759656 & 0.998442 & 1 & 276.008 & $\mathrm{C}$ \\
\hline SRCH08EW & 8 & 0.960657 & 0.855687 & 1 & 606.193 & $\mathrm{D}$ \\
\hline SRCH09EW & 2.803509 & 0.622858 & 0.999238 & 1 & 557.48 & $\mathrm{D}$ \\
\hline CHB012NS & 2.908772 & 0.429311 & 0.813314 & 1 & 360.028 & $\mathrm{D}$ \\
\hline IBRH10EW & 2.102102 & 0.424321 & 0.974303 & 7 & 110.921 & $\mathrm{E}$ \\
\hline
\end{tabular}

*Seismic information, including event index, for the selected records, refers to corresponding events listed in Table 1. Site classifications refer to National earthquake Hazards Reduction Program using $v_{30}$.

TABLE 3: Results for classification by using the proposed method.

\begin{tabular}{lccc}
\hline Observation & Prediction & Long-period & Percentage \\
\hline Non-long-period & 484 & 0 & 100 \\
Long-period & 36 & 228 & 86.4 \\
Total percentage & - & - & 95.2 \\
\hline
\end{tabular}




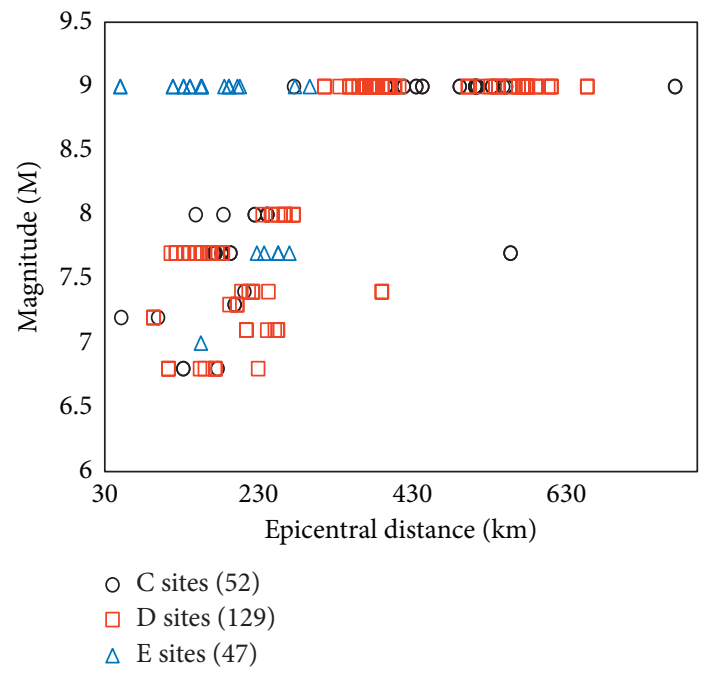

FIgURE 7: Distribution of the identified long-period ground motions.

determine long-period characteristics comparable to the corresponding complete record in view of the entire velocity spectrum. This contrasts with the expected long-period motions whose long-period characteristics are controlled by later-arriving surface waves. Although these three samples share similar long-period characteristics with the positive records in terms of the velocity spectra, they exhibit variations in the mechanism. Thus, it is suggested that the proposed method is suitable for the identification of longperiod motions whose broadband long-period characteristics are controlled by later-arriving long-period waves.

Meanwhile, the latter two samples, CHB002EW and CHB028EW, from Tohuku, M9, earthquake, also show the same mechanism as the positive records, as later-arriving amplitudes make significant contributions to their longperiod characteristics (red dashed lines) in Figures 9(d) and 9(e). Furthermore, in order to investigate the influence of the energy ratio, the two positive records of CHB009EW and TKY024EW described above are involved in the following illustrations, considering that they present similar corner frequencies to those of the latter two samples.

Then, Figure 10 illustrates the comparisons of the Fourier amplitude spectrum in terms of truncated waves and complete records. The frequency domain in Figures $10(a)-10(d)$ is divided into low- and high-frequency band according to the corner frequency $f_{\text {corner. }}$. It is clear that the complete records of CHB002EW and CHB028EW have two dominant frequencies, which are dispatched in low- and high-frequency bands, respectively. This gives rise to a relatively low ratio of energy carried by the later-arriving amplitudes to the total energy of the complete record. In contrast, both positive records have one dominant frequency which is incorporated into the low-frequency band, and there are apparent contributions of the low-frequency band to the total energy.

It is concluded that the proposed method is in favor of the motions whose later-arriving long-period amplitudes provide significant contributions to the total energy in the frequency domain. It is possible that the use of a velocity trace as a surrogate for an acceleration trace in the calculation of the energy ratio may cause variations. This is due to the fact that the amplitudes at high frequencies in the acceleration trace would lose prominence, if their phases are not continuous when integrating to velocity traces. In light of this, the proposed method appears to bias towards the motions which have low energy ratio in the acceleration trace but present the narrowband long-period properties in the velocity trace. However, such motions can be easily identified in the form of the velocity spectrum with one dominant period.

\section{Significance of Long-Period Properties in Terms of Response Spectrum}

It is documented that long-period motions exert significant influences on long-period structures in view of the response spectrum [30]. Thus, the selection of the long-period motions to conduct design and/or performance evaluation for the long-period structures is essential, as receives much attention from engineering communities [3, 33, 34]. In this regard, the significance of long-period characteristics is further examined in the context of the acceleration response spectrum.

Figure 11 exhibits the distribution of the predictors for 748 records used in the training dataset described in pervious section. It can be seen from the figure that the predictors of the identified long-period records are clustered above 0.8 , while the remaining classifications, including the misclassified and non-long-period records, overlap in regions where the predictors mainly range between 0.2 and 0.8 . Then, 748 records were divided into three groups in terms of the predictors: 228 identified long-period ground motions with predictors $\geq 0.8,463$ records with predictors $<0.2$, and 57 records with $0.2 \leq$ predictor $<0.8$, each of which is shown in Figure 11.

Then, a normalized acceleration response spectrum $(\beta$ spectrum) with a $5 \%$ damping ratio is defined as an equation of Sa/PGA (Sa represents values of an acceleration response spectrum; PGA represents the peak value of an acceleration), by which the characteristics of frequency content are able to be reflected by excluding variations of the intensities of the 

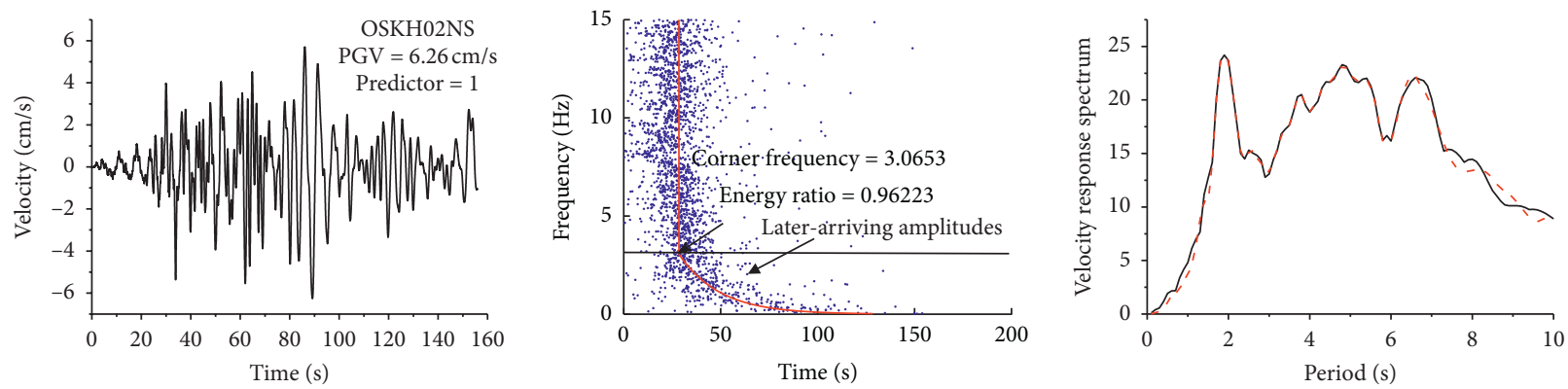

OSKH02NS from acceleration

Scatter points

— OSKH02NS

_. - Truncated wave

(a)
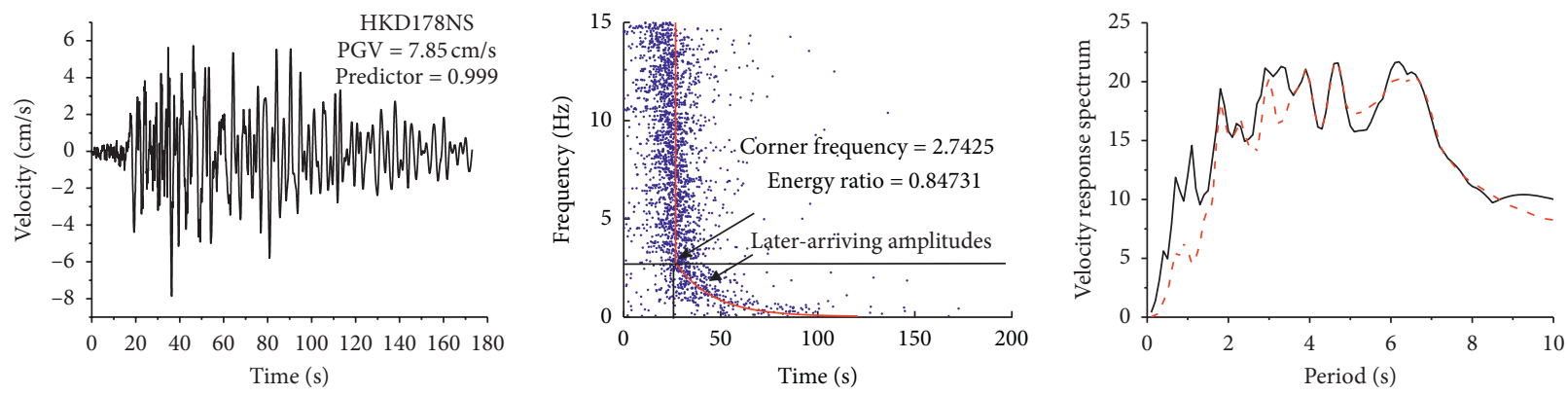

HKD178NS from acceleration
Scatter points

- - - HKD178NS

__ Fitted line

(b)
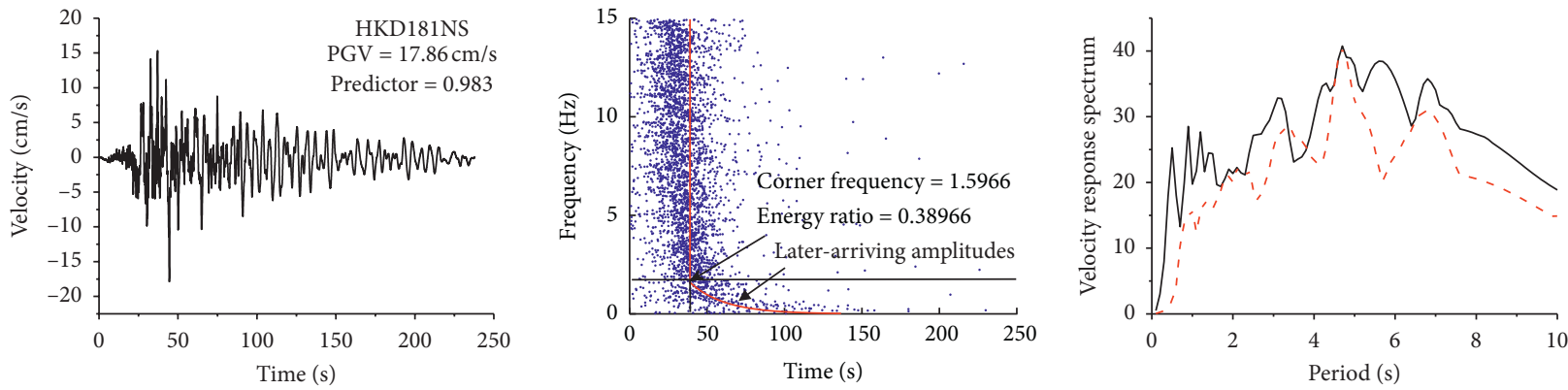

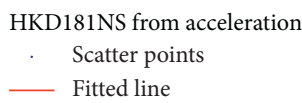

(c)

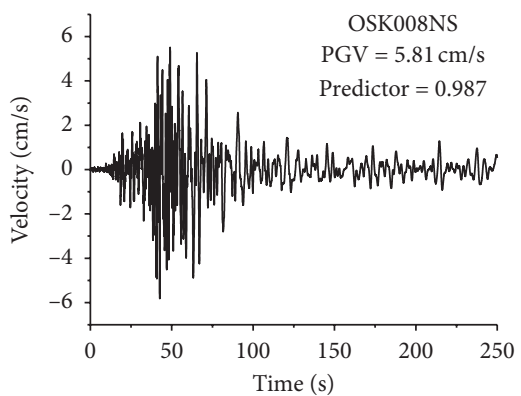

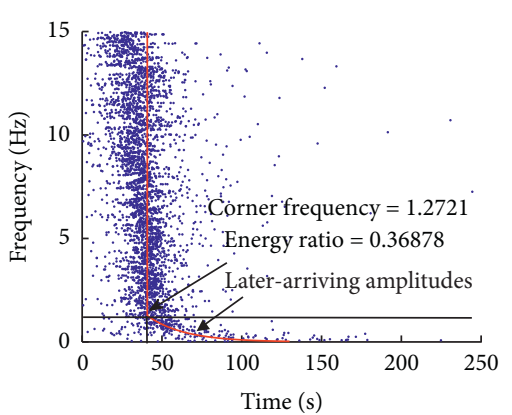

OSK008NS from acceleration

Scatter points

- Fitted line

(d)

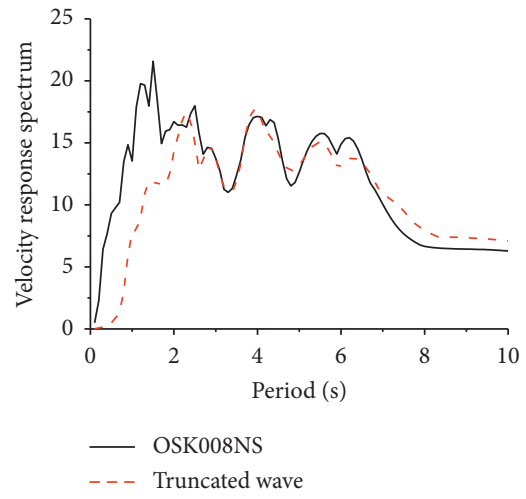

FIgure 8: Continued. 

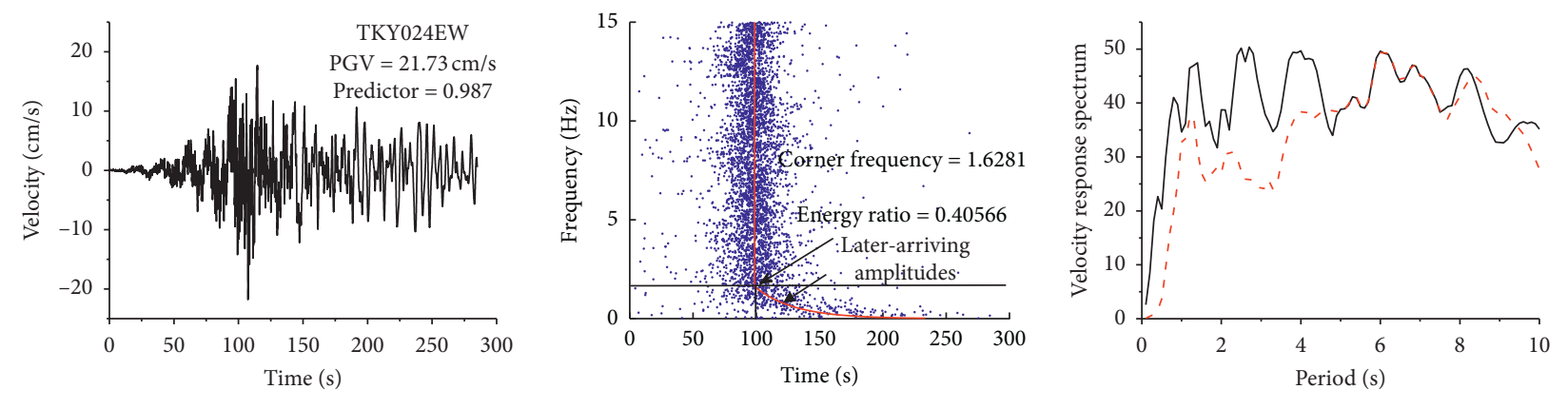

TKY024EW from acceleration

. Scatter points

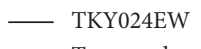

_ Fitted line

(e)
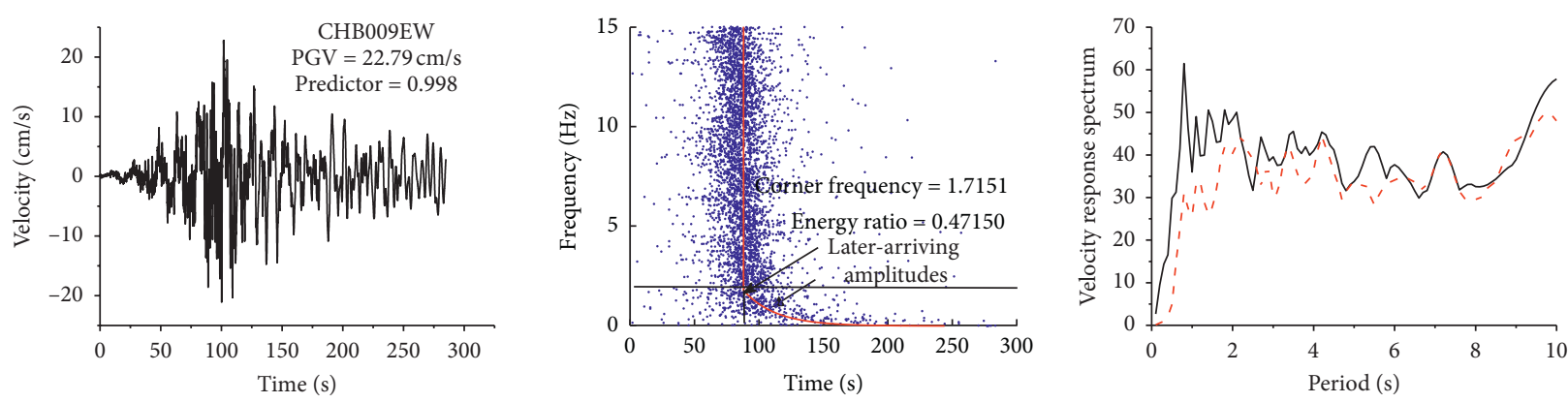

CHB009EW from acceleration

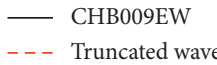

poin

(f)

FiguRE 8: Six samples of the positive records. To better understand the effects of later-arriving amplitudes on long-period properties, each record has three subplots, including velocity-time history, velocity response spectrum, and envelope delay. A truncated wave is obtained in the light of envelope delays (detailed operations noted in this text) and the complete record represents the original record without removing the truncated wave. The records from (a) OSKH02NS, Western Tottori, M7.3; (b) HKD178NS, Tokachi Aftershock, M7.1; (c) HKD181NS, Tokachi Mainshock, M8; (d) OSK008NS, Southeast of Kii peninsula, M7.4; (e) TKY024EW, Tohuku, M9; (f) CHB009EW, Tohuku, M9.

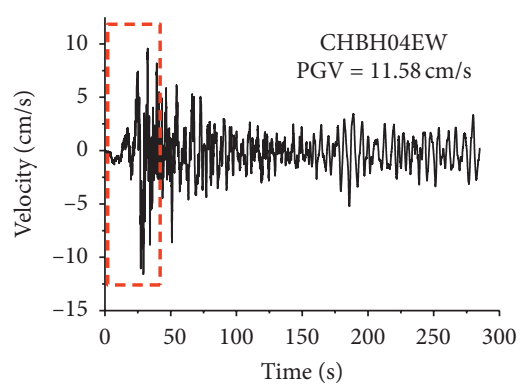

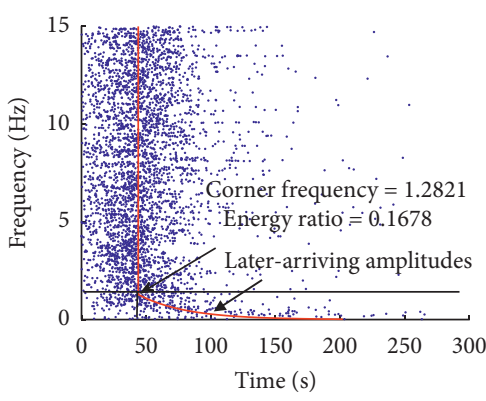

CHBH04EW from acceleration Scatter points

- Fitted line

(a)

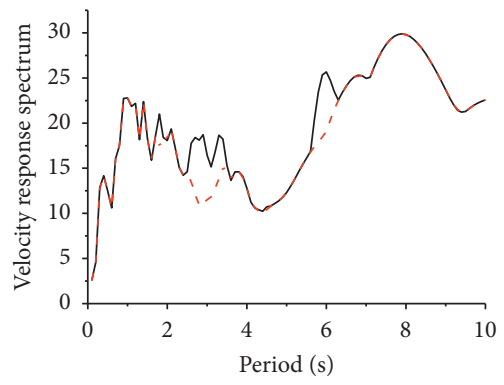

- CHBH04EW - - Truncated wave

FIGURE 9: Continued. 

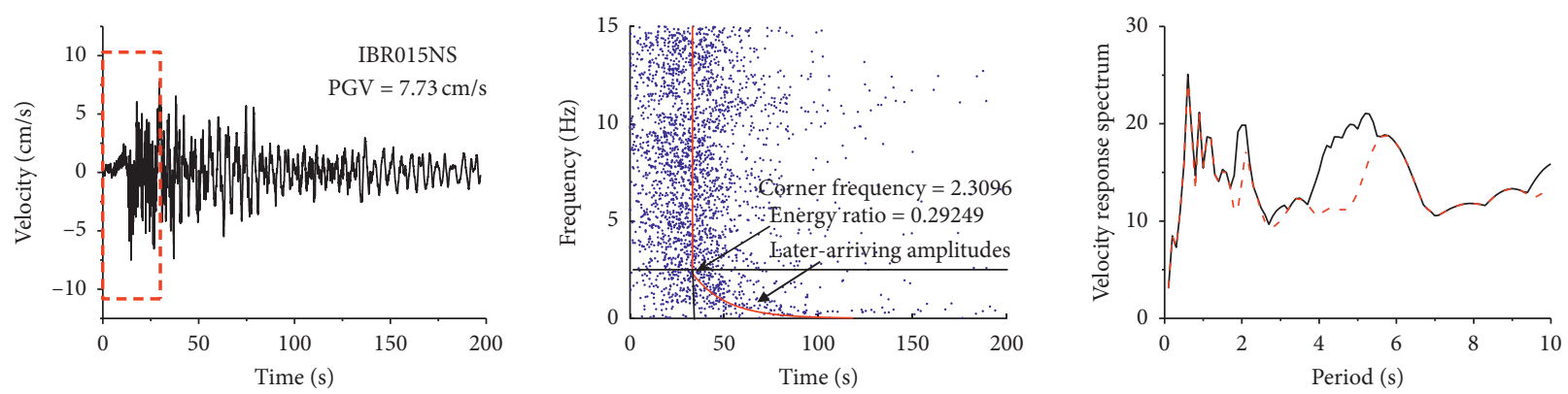

IBR015NS from acceleration
Scatter points _ Fitted line

(b)
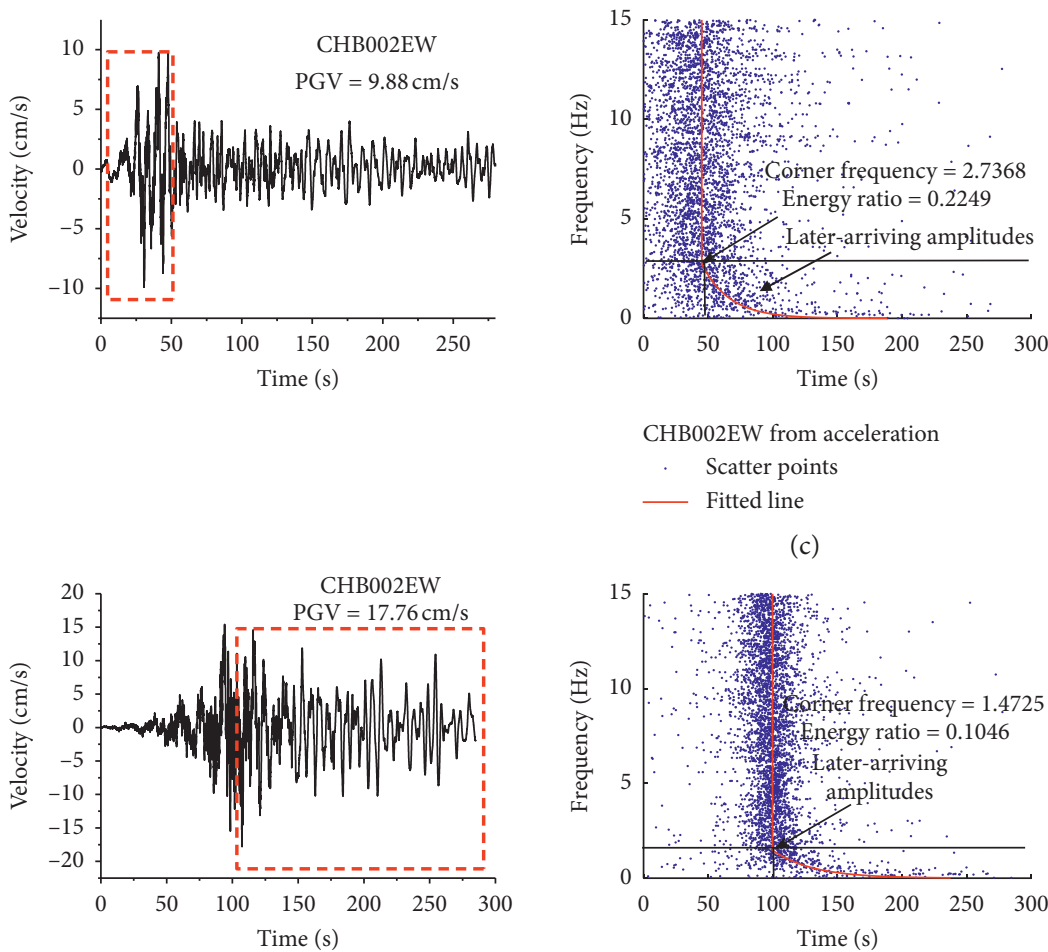

CHB002EW from acceleration - Scatter points

— Fitted line

(c)

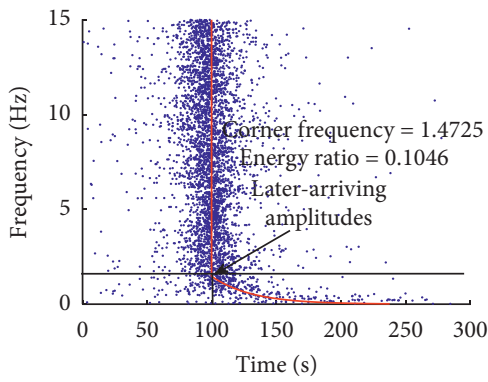

CHB002EW from acceleration Scatter points _ Fitted line

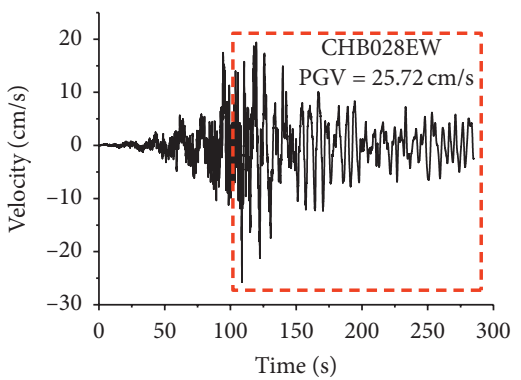

(d)

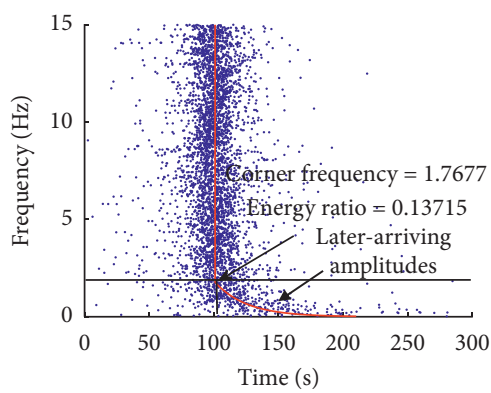

CHB028EW from acceleration
Scatter points
Fitted line

(e)

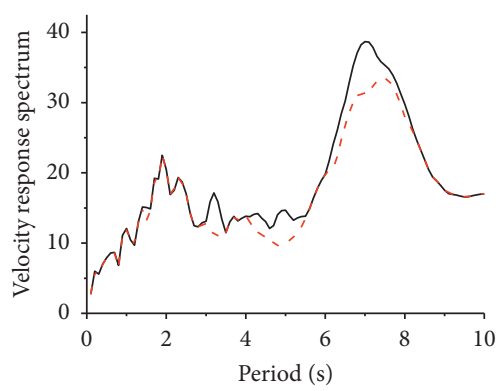

- CHB002EW - - - Truncated wave

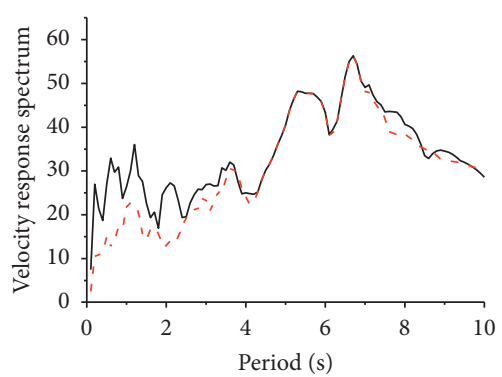

- CHB002EW

- - - Truncated wave

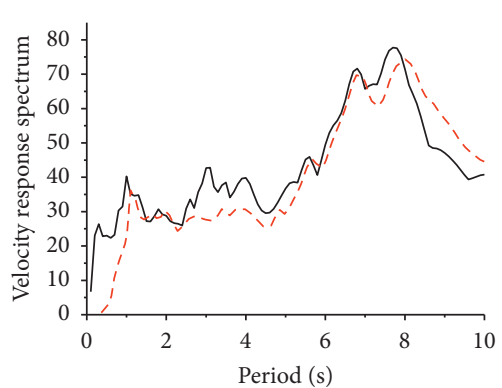

- CHB028EW

- - - Truncated wave

FIGURE 9: Five samples of false positive records; the red dashed lines shown in velocity-time histories mark the truncated waves, which are determined on the basis of envelope delays. The former three records (a)-(c) were recorded from Tohuku aftershock, M7.7, and the latter two records $(\mathrm{d}, \mathrm{e})$ were from Tohuku, M9. 

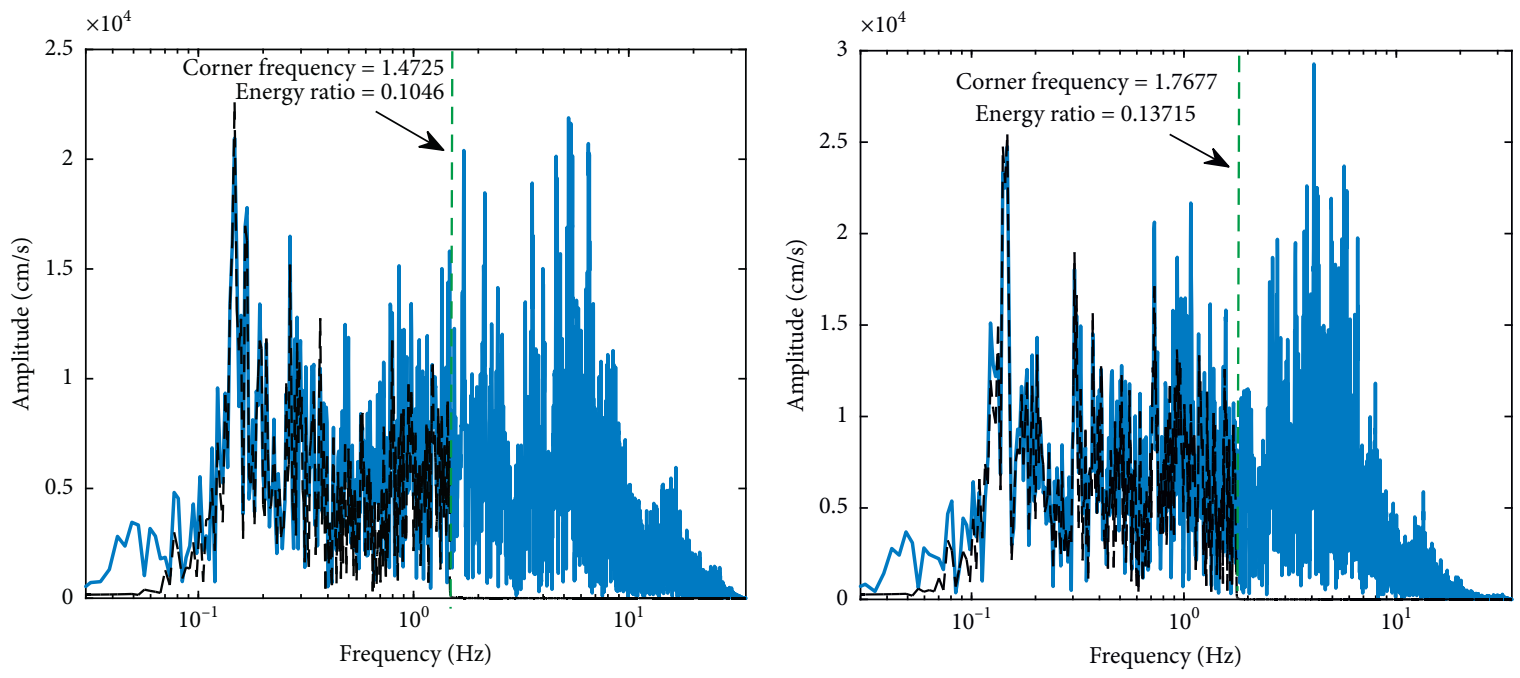

\section{CHB002EW from acceleration \\ Complete record \\ - - - Truncated wave}

(a)

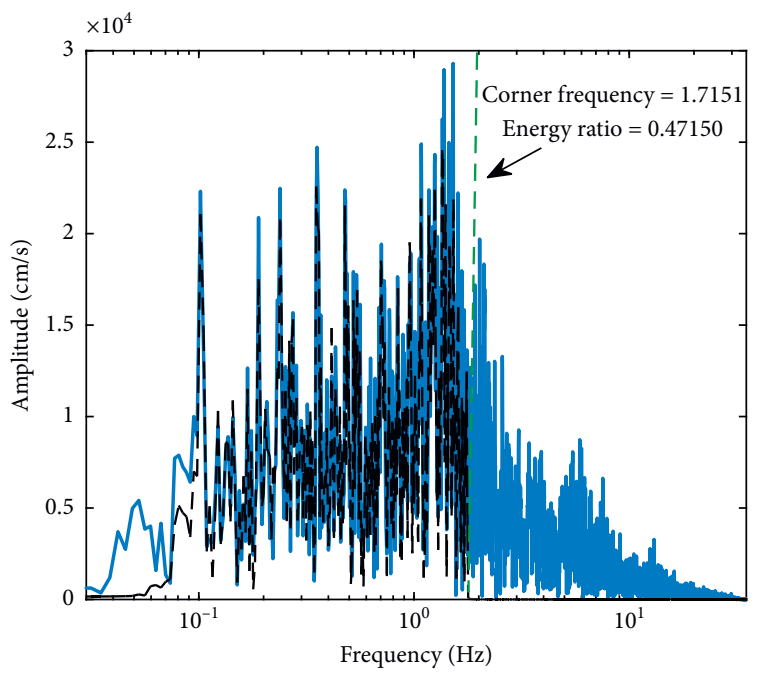

CHB009EW from acceleration

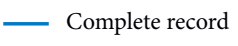

CHB028EW from acceleration

- Complete record

- - - Truncated wave

(b)

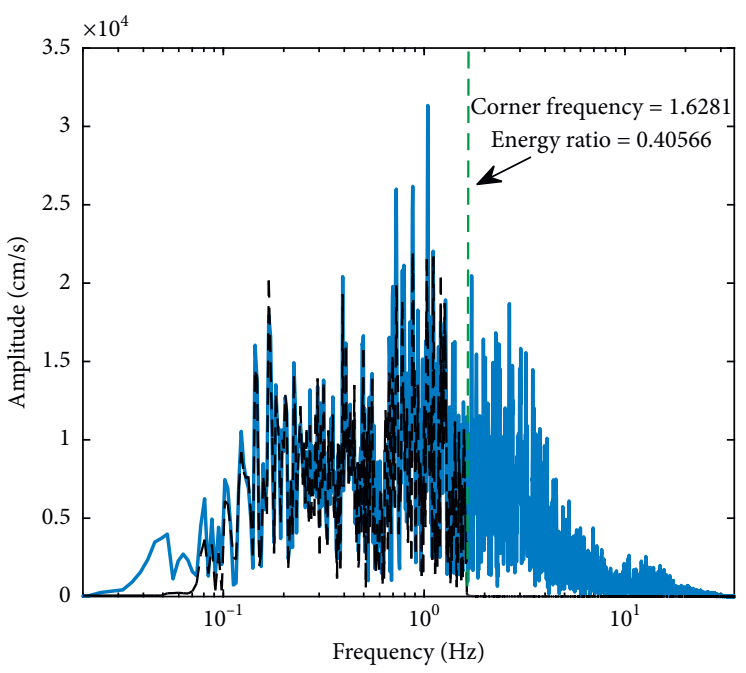

TKY024EW from acceleration

- Complete record

- - - Truncated wave

(c)

(d)

Figure 10: Comparisons of the Fourier amplitude spectra in terms of the complete record and truncated wave; (a) and (b) false positive records from CHB002EW and CHB028EW; (c) and (d) positive records from CHB009EW and TKY024EW. The Fourier amplitudes for the complete record and truncated waves are represented with solid and dashed lines, respectively.

ground motions. As a consequence, the mean $\beta$ response spectrum for each group is illustrated in Figure 12. In general, with an increase of predictors, the significance of the long-period characteristics becomes increasingly obvious. The mean $\beta$ response spectrum of the group with predictors above 0.8 presents overwhelming long-period characteristics among the three groups, and its ordinates at longer periods are considerably greater than those of other groups, with the exclusion of the periods shorter than $1 \mathrm{sec}$.

Besides, comparisons of the mean $\beta$ response spectrum with respect to site classifications are carried out in long- period and non-long-period classifications, respectively, and corresponding results are displayed in Figure 13. As observed from Figure 13(a), local site effects on the identified long-period ground motions are not expected to comply with the rule that the amplifications are closely correlated with site conditions referring to $v_{30}$ (average shear-wave velocity of a profile up to $30 \mathrm{~m}$ ), except for short periods $(\leq 1.5 \mathrm{sec})$ during which the $\mathrm{E}$ sites are larger than both $\mathrm{C}$ and $\mathrm{D}$ sites. This irregular trend pertaining to site classifications is consistent with the conclusions suggested by Joyner [20] and Abraham [35], as amplifications of long-period motions 


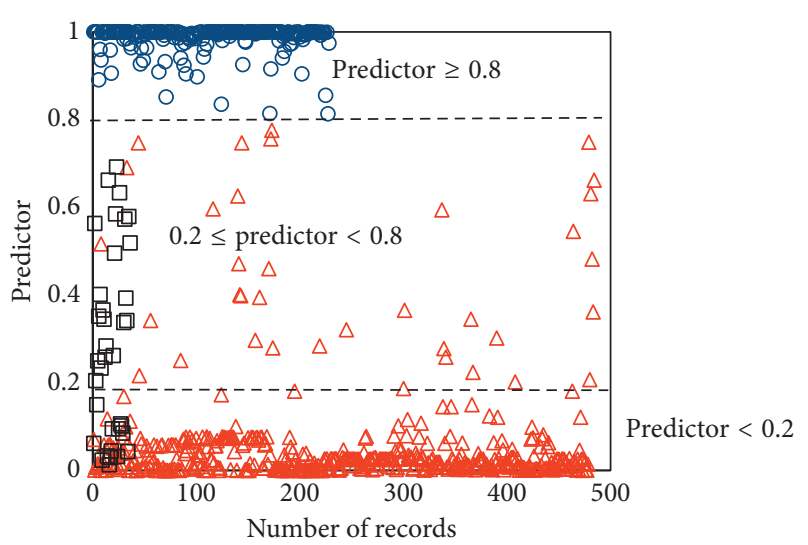

O Identified long-period classification

$\triangle$ Identified non-long-period classification

$\square$ False positive classification

FIGURE 11: Distribution of predictors.

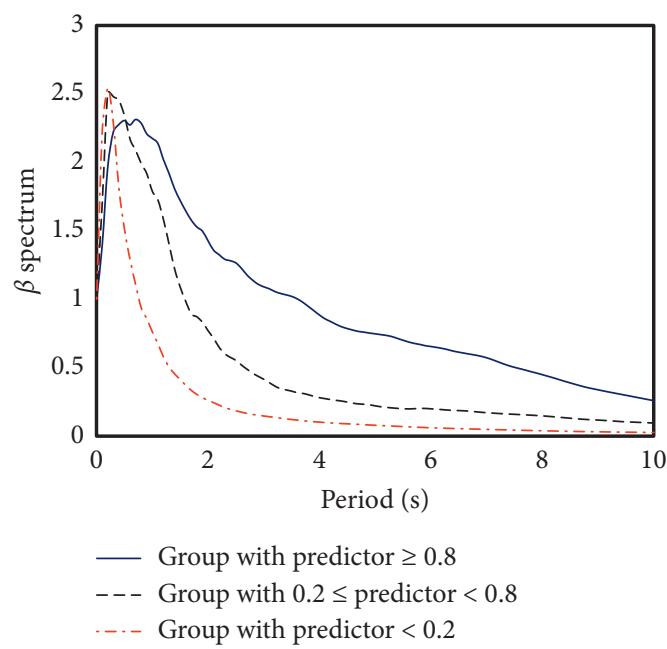

FIGURE 12: Mean normalized acceleration response spectra with respect to predictors.

over long-periods ( $\geq 1 \mathrm{sec}$ ) are mainly dependent upon nonlinear responses caused by irregular geological structures (such as basins). In contrast, Figure 13(b) indicates that the trend for $\beta$ response spectra of the identified non-longperiod motions is correlated with local site effects, as the values of $\mathrm{E}$ sites are significantly greater than those of $\mathrm{C}$ and $\mathrm{D}$ sites from the middle to long-period range. Moreover, it should be noted that the values of the long-period motions are systematically greater than those of non-long-period motions, irrespective of site conditions, accounting for the significance of long-period characteristics of the identified long-period motions.

As illustrated in Figure 13, the variations of long-period characteristics with respect to the predictors are presented, and the proposed method has the potential to provide an estimation of long-period characteristics. Furthermore, the influence of local site effects on amplifications of long-period ground motions differs from that of non-long-period ground motions, suggesting that the amplifications according to classification sites are not applicable to longperiod motions triggered by geological sites.

Therefore, amplifications resulting from distant basins should be incorporated into possible seismic hazard analysis (PSHA) in order to assess performance of long-period structures, considering the fact that the significance of longperiod characteristics derived from non-long-period motions is not comparable to that derived from long-period motions, especially over longer periods.

\section{Conclusion and Discussion}

This paper proposes a method for quantitatively identifying far-field long-period ground motions. Envelope delays are obtained from the calculation of an acceleration-time history by means of phase derivatives, wherein the relative arrival times in the envelope of acceleration series are dependent on frequencies.

Due to the amplification of surface waves, the laterarriving components with low frequencies carry the large energy value relative to the total energy of a ground motion. In this regard, the main principle pertaining to the calibration of long-period ground motions is developed with the aid of the predictive variables: (1) the combination of the corner frequency $f_{\text {corner }}$ with corresponding arrival time $t\left(f_{\text {corner }}\right)$ determines the later-arriving long-period waves in terms of frequency and time domains; (2) the energy ratio $E_{\text {ratio }}$ is regarded as a quantitative index for energy in order to estimate the intensity of later-arriving long-period waves relative to the total energy. For the purpose of separating the long-period ground motions from non-long-period ground motions, the threshold value of 0.8 as the result of logistic regression is proposed.

The analysis of the classification results associated with positive and false positive records provides insight into the effectiveness of the proposed method, by which the differentiation of long-period motions whose long-period properties are determined by the later-arriving amplitudes from those determined by early long-period amplitudes is attained.

Furthermore, comparisons of mean $\beta$ response spectra with respect to the predictors indicate that the long-period properties are consistent with the predictor-based groups, suggesting that the predictors are suitable for the estimation of the long-period properties. In addition, preliminary investigations relating local site effects to long-period properties for long-period and non-long-period motions, respectively, suggest that amplifications of long-period motions, resulting from distant basins, are independent of site classifications based on site properties at shallow depths. This means that such motions should be incorporated into a set of ground motions selected for design and/or performance assessment of long-period structures, as long-period ground motions resulting from distant sedimentary sites are not often considered in the application of PSHA.

It is noteworthy that the proposed method specializes in the determination of broadband long-period properties, which are presented in the form of later-arriving long-period amplitudes. However, the method may lose efficiency in determining the motions whose long-period properties are 


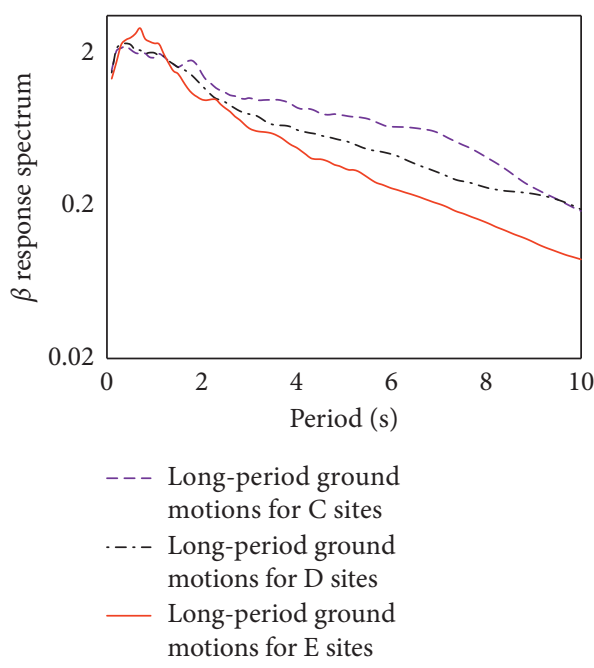

(a)

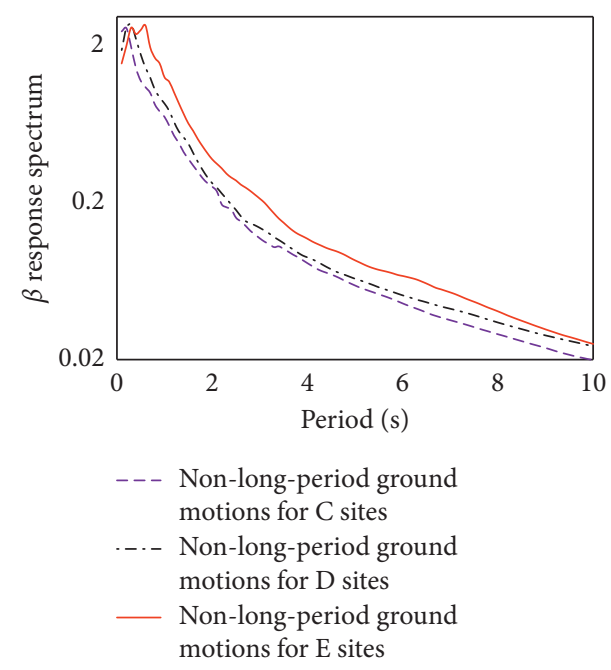

(b)

FIGURE 13: Mean normalized acceleration response spectra for long-period (a) and non-long-period (b) ground motions in terms of site classifications.

in the form of narrowband frequencies. Alternatively, such records can be detected by inspecting their velocity response spectrum with one dominant period.

\section{Data Availability}

The data used for conducting classifications are available from the corresponding author authors upon request.

\section{Conflicts of Interest}

The authors declare that they have no conflicts of interest.

\section{Acknowledgments}

The authors thank support from the National Natural Science Foundation of China, with award number 51478068, and also acknowledge the National Research Institute for Earthquake Science and Disaster Prevention (K-NET and KiK-net), which offer assistances for access to the considerable number of dataset for studies.

\section{Supplementary Materials}

The data file contains the records used in the manuscript. Each record has information, including stations, corner frequency, energy ratio, predictor, event index, epicentral distance and sites. Further, the two variables, corner frequency and energy ratio (calculations for them seen in manuscript), are used to form the quantitative calibration for determining far-field long-period and non-far-field longperiod. Predictor is an index for evaluating the likelihood of determining a long-period ground motion in sense of longperiod characteristics. Event index, which represents the sequence of the events used in manuscript, refers to the Table 1 for details in manuscript. Epicentral distance for each record is obtained based on calculation of distance to source. Site stands for site classifications referred to NEHRP
(National earthquake Hazards Reduction Program) in terms of v_30 (average shear-wave velocity up to $30 \mathrm{~m}$ of a profile). Note that the records are from K-NET and KiK-net strong motions networks, Japan. Thus, information for the stations are available from the following web site: http://www. kyoshin.bosai.go.jp. (Supplementary Materials)

\section{References}

[1] T. C. Shin and T. L. Teng, "An overview of the 1999 Chi-Chi, Taiwan, earthquake," Bulletin of the Seismological Society of America, vol. 91, no. 5, pp. 895-913, 2001.

[2] K. Hatayama, "Lessons from the 2003 Tokachi-oki, Japan, earthquake for prediction of long-period strong ground motions and sloshing damage to oil storage tanks," Journal of Seismology, vol. 12, no. 2, pp. 255-263, 2008.

[3] I. Takewaki, S. Murakami, K. Fujita, S. Yoshitomi, and M. Tsuji, "The 2011 off the Pacific coast of Tohoku earthquake and response of high-rise buildings under long-period ground motions," Soil Dynamics and Earthquake Engineering, vol. 31, no. 11, pp. 1511-1528, 2011.

[4] N. Yamada and T. Iwata, "Long-period ground motion simulation in the Kinki area during the MJ 7.1 foreshock of the 2004 off the Kii peninsula earthquakes," Earth, Planets and Space, vol. 57, no. 3, pp. 197-202, 2005.

[5] G.-Q. Wang, G.-Q. Tang, D. M. Boore et al., "Surface waves in the Western Taiwan Coastal plain from an aftershock of the 1999 Chi-Chi, Taiwan, earthquake," Bulletin of the Seismological Society of America, vol. 96, no. 3, pp. 821-845, 2006.

[6] K. Koketsu and H. Miyake, "A seismological overview of longperiod ground motion," Journal of Seismology, vol. 12, no. 2, pp. 133-143, 2008.

[7] B. Fatahi and S. H. R. Tabatabaiefar, "Effects of soil plasticity on seismic performance of mid-rise building frames resting on soft soils," Advances in Structural Engineering, vol. 17, no. 10, pp. 1387-1402, 2014.

[8] H. R. Tabatabaiefar, B. Fatahi, K. Ghabraie, and W.-H. Zhou, "Evaluation of numerical procedures to determine seismic response of structures under influence of soil-structure 
interaction," Structural Engineering and Mechanics, vol. 56, pp. 27-47, 2015.

[9] S. H. R. Tabatabaifar, B. Fatahi, and B. Samali, "Finite difference modelling of soil-structure interaction for seismic design of moment resisting building frames," Australian Geomechanics Journal, vol. 47, pp. 113-120, 2012.

[10] A. Massumi and H. R. Tabatabaiefar, "Effects of soil structure interaction on seismic behavior of ductile reinforced concrete moment resisting frames," in World Housing Congress on Affordable Quality Housing, Putra, Malaysia, 2007.

[11] K. C. M. Fajardo and A. S. Papageorgiou, "Response of tall buildings to base rocking induced by Rayleigh waves," Earthquake Engineering and Structural Dynamics, vol. 47, pp. 1755-1773, 2018.

[12] P. G. Somerville, N. F. Smith, R. W. Graves, and N. A. Abrahamson, "Modification of empirical strong ground motion attenuation relations to include the amplitude and duration effects of rupture directivity," Seismological Research Letters, vol. 68, no. 1, pp. 199-222, 1997.

[13] J. W. Baker, "Quantitative classification of near-fault ground motions using wavelet analysis," Bulletin of the Seismological Society of America, vol. 97, no. 5, pp. 1486-1501, 2007.

[14] C. Zhai, Z. Chang, S. Li, Z. Chen, and L. Xie, "Quantitative identification of near-fault pulse-like ground motions based on energy," Bulletin of the Seismological Society of America, vol. 103, no. 5, pp. 2591-2603, 2013.

[15] D. M. Boore, "Phase derivatives and simulation of strong ground motions," Bulletin of the Seismological Society of America, vol. 93, no. 3, pp. 1132-1143, 2003.

[16] R. W. Graves, A. Pitarka, and P. G. Somerville, "Groundmotion amplification in the Santa Monica area: effects of shallow basin-edge structure," Bulletin of the Seismological Society of America, vol. 88, pp. 1224-1242, 1998.

[17] H. Kawase and K. Aki, "A study on the response of a soft basin for incident $S, P$, and Rayleigh waves with special reference to the long duration observed in Mexico City," Bulletin of the Seismological Society of America, vol. 79, pp. 1361-1382, 1989.

[18] K. Koketsu, K. Hatayama, T. Furumura, Y. Ikegami, and S. Akiyama, "Damaging long-period ground motions from the 2003 Mw 8.3 Tokachi-oki, Japan earthquake," Seismological Research Letters, vol. 76, no. 1, pp. 67-73, 2005.

[19] T. Furumura and T. Hayakawa, "Anomalous propagation of long-period ground motions recorded in Tokyo during the 23 October $2004 \mathrm{Mw} 6.6$ Niigata-ken Chuetsu, Japan, earthquake," Bulletin of the Seismological Society of America, vol. 97, no. 3, pp. 863-880, 2007.

[20] W. B. Joyner, "Strong motion from surface waves in deep sedimentary basins," Bulletin of the Seismological Society of America, vol. 90, pp. 87-93, 2000.

[21] C. Beauval, "Quantification of frequency-dependent lengthening of seismic ground-motion duration due to local geology: applications to the Volvi area (Greece)," Bulletin of the Seismological Society of America, vol. 93, no. 1, pp. 371-385, 2003.

[22] J. R. Abraham, C. G. Lai, and A. Papageorgiou, "Basin-effects observed during the 2012 Emilia earthquake sequence in Northern Italy," Soil Dynamics and Earthquake Engineering, vol. 78, pp. 230-242, 2015.

[23] I. Okawa, T. Kashima, S. Koyama, M. Iiba, and M. Çelebi, "Summary of recorded building responses during the 2011 off the Pacific Coast of Tohoku earthquake with some implications to design motions," in Proceedings of the International Symposium on Engineering Lessons Learned from the 2011
Great East Japan Earthquake, pp. 1-4, Tokyo, Japan, March 2012.

[24] Y. Yuzawa and K. Kudo, "Empirical predictive model for long-period (1-15 sec) ground motion on hard rocks," Journal of Structural and Construction Engineering (Transactions of AIJ), vol. 76, no. 661, pp. 519-526, 2011.

[25] M. Zamora and R. Riddell, "Elastic and inelastic response spectra considering near-fault effects," Journal of Earthquake Engineering, vol. 15, no. 5, pp. 775-808, 2011.

[26] T. Furumura, S. Takemura, S. Noguchi et al., "Strong ground motions from the 2011 off-the Pacific-Coast-of-Tohoku, Japan $(\mathrm{Mw}=9.0)$ earthquake obtained from a dense nationwide seismic network," Landslides, vol. 8, no. 3, pp. 333-338, 2011.

[27] S. K. Shahi and J. W. Baker, "An efficient algorithm to identify strong-velocity pulses in multicomponent ground motions," Bulletin of the Seismological Society of America, vol. 104, no. 5, pp. 2456-2466, 2014.

[28] D. S. Panealla, M. E. Tornello, and C. D. Frau, "A simple and intuitive procedure to identify pulse-like ground motions," Soil Dynamics and Earthquake Engineering, vol. 94, pp. 234-243, Mar 2017.

[29] A. Agresti, Categorical Data Analysis, Wiley, New York, NY, USA, 2002.

[30] M. Celebi, Y. Hisada, R. Omrani, S. F. Ghahari, and E. Taciroglu, "Responses of two tall buildings in Tokyo, Japan, before, during, and after the M9.0 Tohoku earthquake of 11 March 2011,” Earthquake Spectra, vol. 32, 2016.

[31] H. Takabatake and Y. Kitada, "Approximate method of estimating seismic performance of high-rise buildings with oildampers," Structural Design of Tall and Special Buildings, vol. 27, p. e1473, 2018.

[32] D. M. Boore, "Basin waves on a seafloor recording of the 1990 Upland, California, earthquake: implications for ground motions from a larger earthquake," Bulletin of the Seismological Society of America, vol. 89, pp. 317-324, 1999.

[33] I. Takewaki, K. Fujita, and S. Yoshitomi, "Uncertainties in long-period ground motion and its impact on building structural design: case study of the 2011 Tohoku (Japan) earthquake," Engineering Structures, vol. 49, pp. 119-134, 2013.

[34] I. Takewaki, "Toward greater building earthquake resilience using concept of critical excitation: a review," Sustainable Cities and Society, vol. 9, pp. 39-53, 2013.

[35] J. Ronald Abraham, C. G. Lai, and A. Papageorgiou, "Basineffects observed during the 2012 Emilia earthquake sequence in Northern Italy," Soil Dynamics and Earthquake Engineering, vol. 78, pp. 230-242, 2015. 


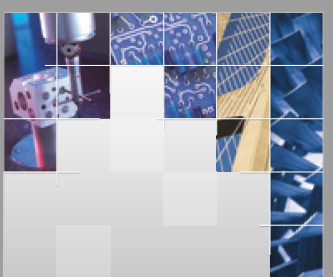

\section{Enfincering}
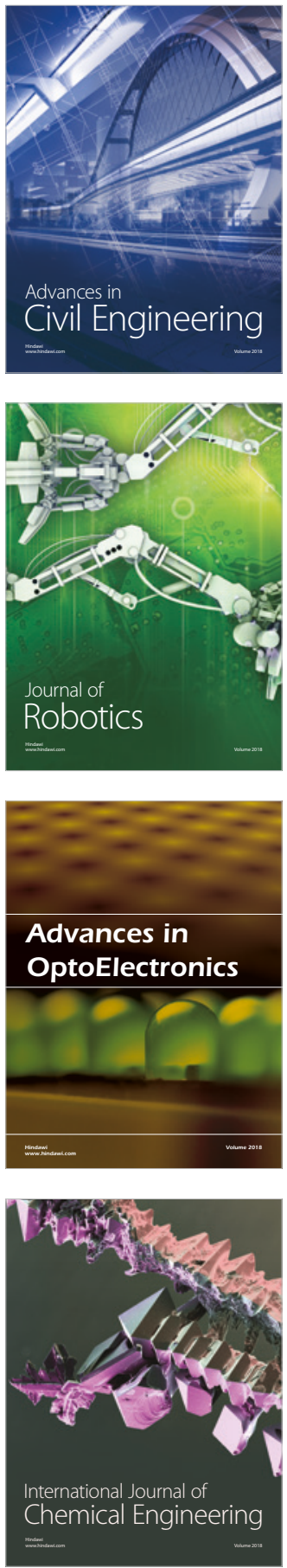

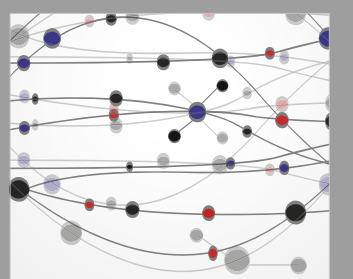

\section{Rotating \\ Machinery}

The Scientific World Journal

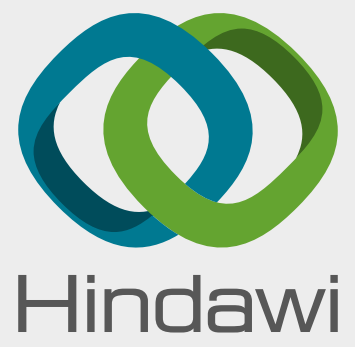

Submit your manuscripts at

www.hindawi.com
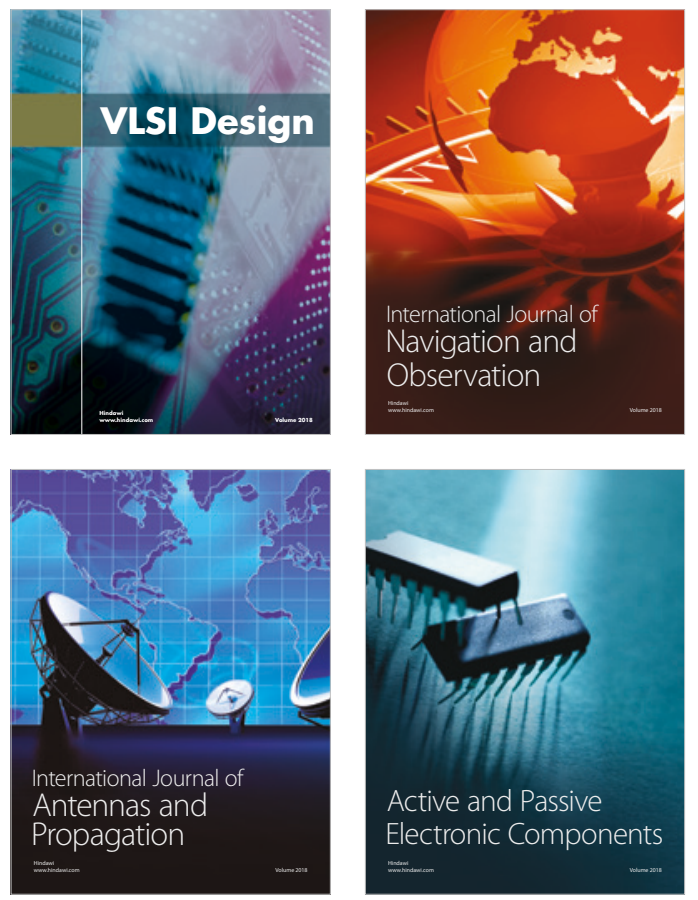
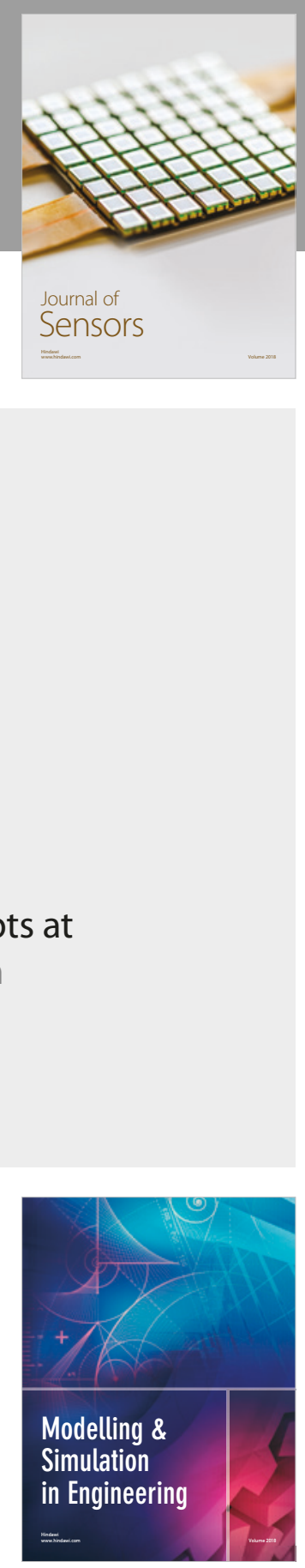

\section{Advances \\ Multimedia}
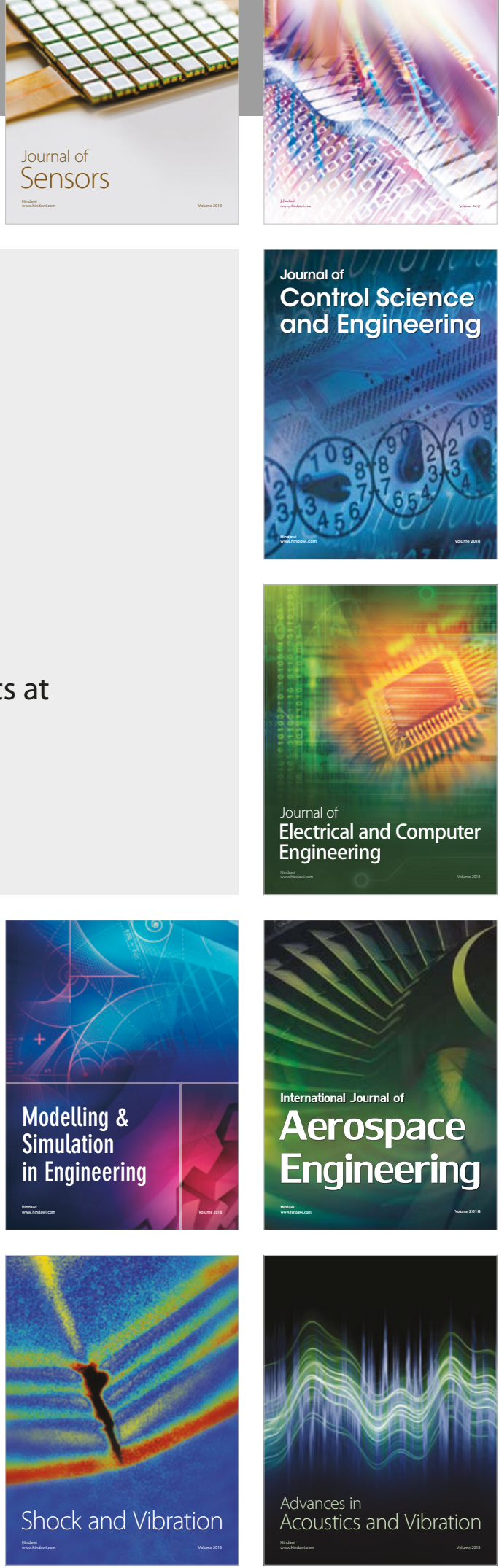